\title{
Technical Issues Assoclated with In Situ Vitrification of the INEL Subsurface Disposal Area
}

\section{Volume 3: Application of Technical Issues to the TRU-Contaminated Pits and Trenches}

\author{
Carl M. Stoots \\ Steven O. Bates \\ Richard A. Callow \\ Kristy A. Campbell \\ Richard K. Farnsworth \\ Gretchen K. Krisman \\ Michael G. McKellar \\ David F. Nickelson \\ Calvin E. Slater
}

\author{
Published July 1992 \\ Idaho National Engineering Laboratory \\ EG\& G Idaho, Inc. \\ Idaho Falls, Idaho 83415
}

Propared for the

U.S. Dopartment of Energy

Office of Environmental Restoration and Waste Management

Under DOE Idaho Flald Office

Contract DE-AC07-76ID01570 
Technical issues Associated with In Situ Vitrification of the INEL Subsurface Disposal Area

Volume 3: Application of Technical Issues to the TRU-Contaminated Pits and Trenches

Prepared by:

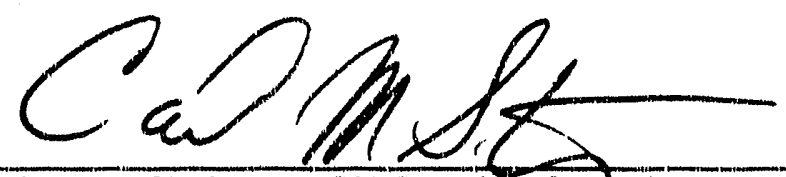

Carl M. Stools, Chairman ISV Steering Contmittee $\frac{\operatorname{lame} 26,1992}{\text { Date }}$

Gee 26,1992

Approved by:

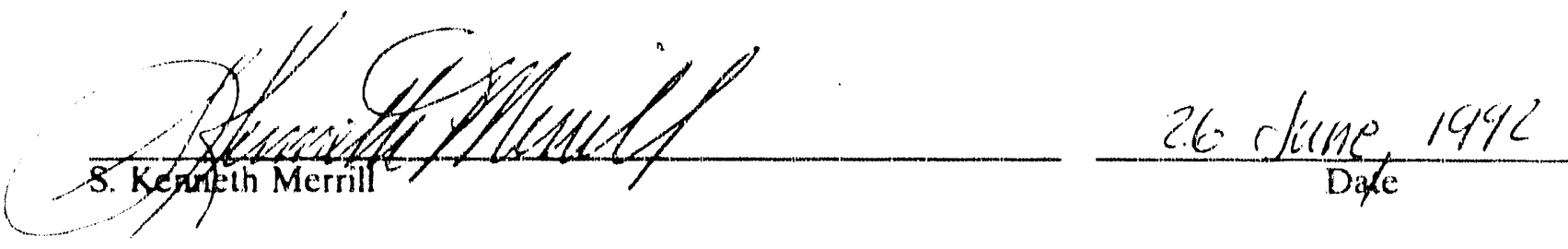




\begin{abstract}
In situ vitrification (ISV) has been identified as an alternative technology for remediation of the acid pit and transuranic pits and trenches (TRU PTs) at the Idaho National Engineering Laboratory (INEL) Subsurface Disposal Area (SDA). However, a number of technical issues must be resolved before ISV can be considered applicable to these waste sites. To assist in the ISV technology evaluation, an ISV Steering Committee was formed to identify, prioritize, and develop closure roadmaps for technical issues associated with ISV application at the SDA. The activities of the ISV Steering Committee are summarized in a three-volume report. Volume 1 identifies the systematic approach used to identify and prioritize the ISV technical issues and briefly discusses the rnethodology that will be employed to resolve these issues. Volumes 2 and 3 discuss each technical issue in greater detail and suggest specific closure roadmaps to be used in resolving technical issues associated with ISV at the SDA Acid Pit and TRU-PTs, respectively. 'The three-volume report is a working document that will be updated as necessary to reflect current evaluation strategy for the ISV technology. This is Volume 3.
\end{abstract}




\section{SUMMARY}

The Idaho National Engmeering Laboratory (INEL) is currently evaluating different technology alternatives for remediating waste sites at its Subsurface Disposal Area (SDA). Currently, in situ vitritication (ISV) is being evaluated for remedial applications within the SDA. While ISV is relatively well developed for contaminated soils, a number of issues need to be resolved before ISV can be applied to the SDA.

As a result, an ISV Steering Committee was formed to help evaluate ISV technology for remediating the INEL SDA. The purpose of the ISV Steering Committee is to define, prioritize, and develop roadmaps for closure of technical issues associated with the proposed application of ISV to the SDA. The activities of the ISV Steering Committee are summarized in a three-volume report. Volume 1 identifies the methods used for identifying and prioritizing ISV technical issues associated with two operable units at the SDA the Acid Pit and transuranic-contaminated waste pits and trenches (TRU-PTs), while briefly discussing the methodologies that will be employed to resolve these issucs. Volumes 2 and 3 discuss each technical issue and specifically address a suggested resolution for technical issues associated with the SDA Acid Pit and TRU..PTs, respectively.

In Volume 3, specific closure roadmaps are identified for the 35 technical issues determined to be applicable to the TRU-PTs. Based on the prioritization criteria discussed in Volume 1 , the two most important ISV technical issues for the TRU-PTs are:

- Possibility of criticality is avoided

- Increases in offgas due to the breach of pressurized sealed containers are contained and processed adequately by the offgas treatment system.

Criticality is an issue stemming from the transuranic material buried in the TRU-PTs. Although previous studies have shown it is improbable a critical condition will develop during ISV processing of soils, a number of additional criticality concerns exist with buried waste processing. Provided there is enough material present, the material is sufficiently concentrated, and the moderation properties of the surrounding waste materials are suitable, these transuranic materials are capable of sustaining a nuclear chain reaction. To close the issue, the report recommends (a) characterize the TRU..PT to determine presence, location, condition, and types of transuranic material, (b) identify the mechanisms by which transuranics and moderating material may be moved around or transformed during ISV processing and identify which of these mechanisms could result in a critical condition, (c) use information on the concentration of transuranic material in the TRU-P'T to estimate the final concentration of transuranics in the solidified ISV waste form and determine if this is sufficient io produce a critical condition, (d) use experimental tracer studies to evaluate the potential transport of transuranics during ISV operations, (e) use site characterization data to estimate the potential for a critical condition to occur in any of the buried waste packages prior to coming in contact with the downward moving ISV melt front, and (f) evaluate any other perceived mechanisms that could produce a criticality.

As the mell approaches a sealed container, the pressures and temperatures within the container increase and the container's strength and seals are weakened. Eventually, the container seal is breached and releases the potentially pressurized contents. Large pressure transients may affect both the offgas hood and treatment system. Transients may pressurize the normally negative pressure operation of the offgas system, promote melt splatter, exceed the treatment system capabilities, and possibly breach the offgas system and release unacceptable levels of contaminants to the environment or pose unacceptable risks to workers or the public. 
To resolve the sealed container issue, the effects of container size, contents, and depth on container release mechanisms and rates must be determined. These mechanisms can be simulated with process models and experimental test data. After a "worst case" scenario is identified, the bounding pressure transients can be determined. Design modifications to the offgas confinement and treatment system may be required to mitigate the issue. 


\section{ACKNOWLEDGMENTS}

The authors would like to thank the following people for their contributions to the report: R. W. Bonnenberg, C. Casey, V. Esparza, L. L. Fritz, C. J. Graden, M. Herd, P. Nagata, N. L. Smith, P. A. Sloan, P. R. Stoots. 


\section{CONTENTS}

ABSTRACT $\ldots \ldots \ldots \ldots \ldots \ldots \ldots \ldots \ldots \ldots \ldots \ldots \ldots \ldots \ldots \ldots \ldots \ldots \ldots \ldots \ldots$

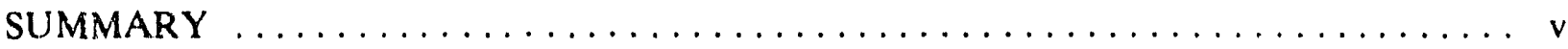

ACKNOWLEDGMENTS $\ldots \ldots \ldots \ldots \ldots \ldots \ldots \ldots \ldots \ldots \ldots \ldots$ vii

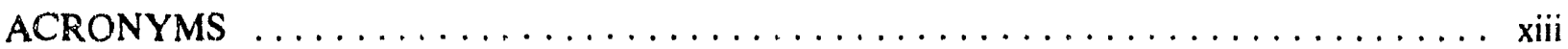

1. INTRODUCTION $\ldots \ldots \ldots \ldots \ldots \ldots \ldots \ldots \ldots \ldots \ldots \ldots \ldots \ldots \ldots \ldots \ldots$

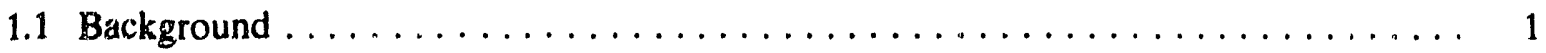

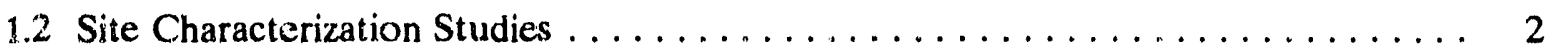

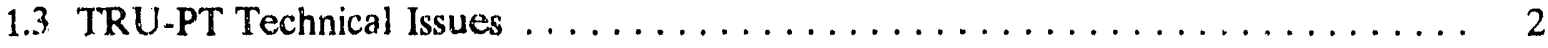

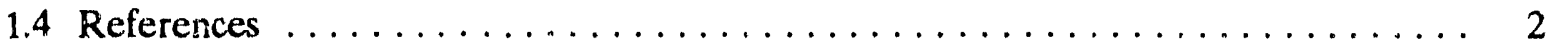

2. ENVIRONMENTAL ISSUES $\ldots \ldots \ldots \ldots \ldots \ldots \ldots \ldots \ldots \ldots \ldots \ldots$

2.1 Durability/Quality of the Product Is Acceptable $\ldots \ldots \ldots \ldots \ldots \ldots \ldots \ldots$

2.1 .1 Description . . . . . . . . . . . . . . . . . . . . . . 8

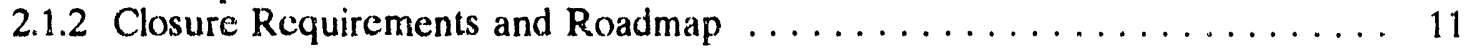

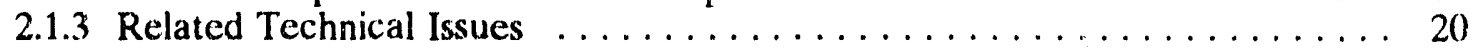

2.1 .4 References ................................... 20

2.2 Subsurface Contaminant Migration during Processing

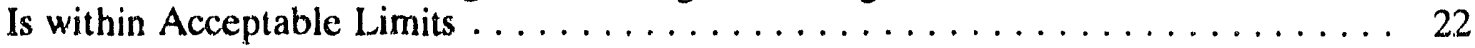

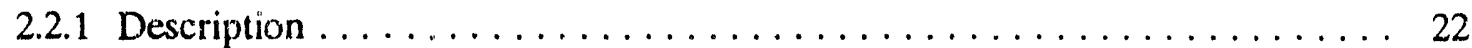

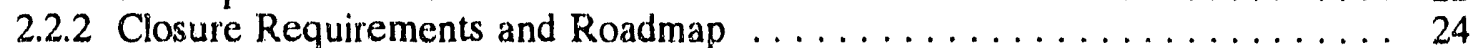

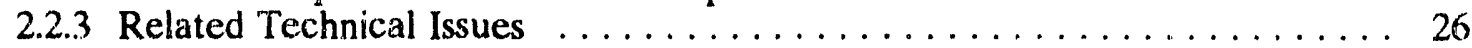

2.2 .4 References .................................. 27

2.3 Any Residual Waste Is Acceptable $\ldots \ldots \ldots \ldots \ldots \ldots \ldots \ldots \ldots \ldots \ldots$

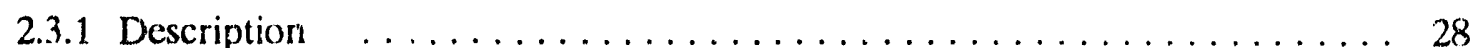

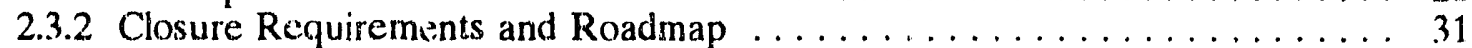

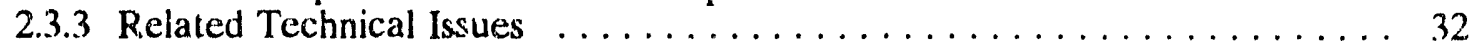

2.3.4 References ................................... 34

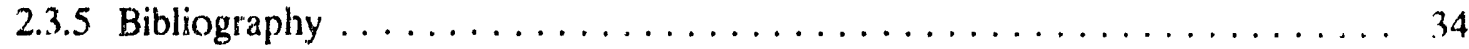

2.4 Secondary Waste Streams (Effluents from the

Offgas Treatment System, Scrub Solutions,

HEPA Filters, Decontamination Solutions,

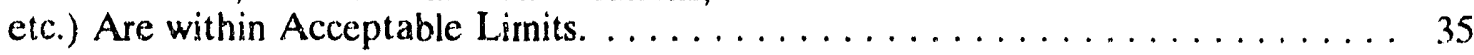

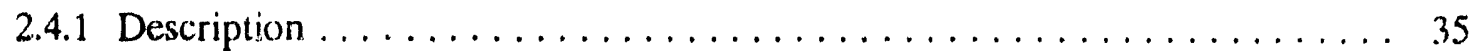

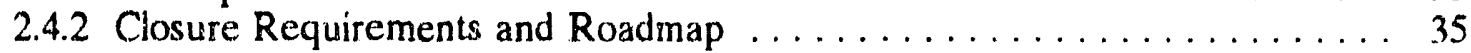

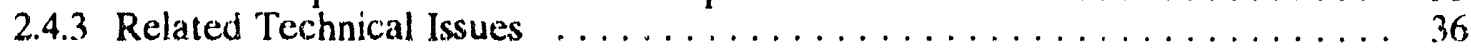




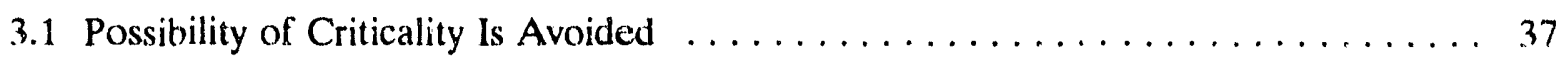

3.1 .1 Description . . . . . . . . . . . . . . . . . . . . . 37

3.1 .2 Closure Requirements and Roadmap $\ldots \ldots \ldots \ldots \ldots \ldots \ldots \ldots \ldots \ldots$

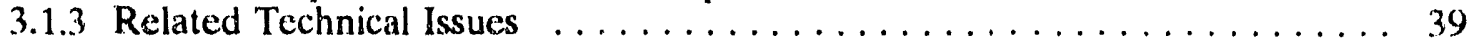

3.1 .4 References . . . . . . . . . . . . . . . . . . . . . . 39

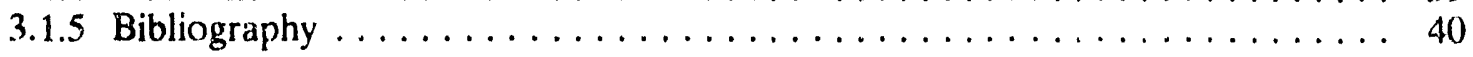

3.2 Hood and Offgas Treatment System Seals Maintain Integrity . . . . . . . . 41

3.2 .1 Description . . . . . . . . . . . . . . . . . . . . . 41

3.2 .2 Closure Requirements and Roadmap $\ldots \ldots \ldots \ldots \ldots \ldots \ldots \ldots \ldots \ldots$

3.2 .3 Related Technical Issues . . . . . . . . . . . . . . . . . . . . . . . 49

3.2 .4 References . . . . . . . . . . . . . . . . . . . . . . . . . 49

3.3 Hood and Offgas Treatment System Handle Pressure Transients . . . . . . . . . . 51

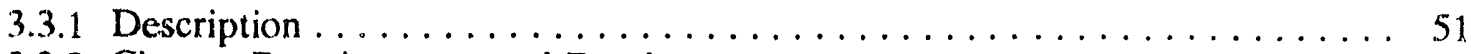

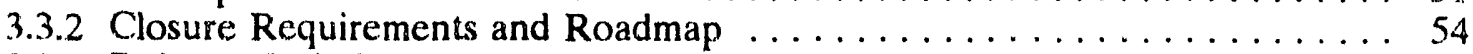

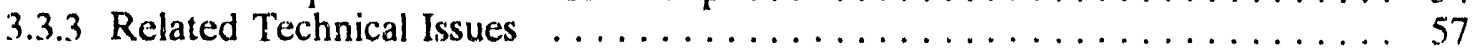

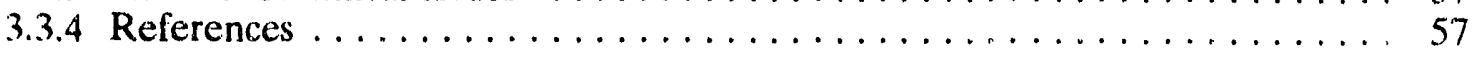

3.4 Risks Due to Exposed Waste Are within Acceptable Limits . . . . . . . . . 59

3.4 .1 Description . . . . . . . . . . . . . . . . . . . . . 59

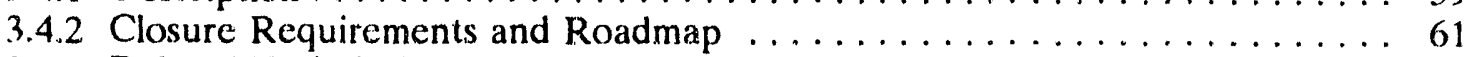

3.4.3 Related Technical Issues $\ldots \ldots \ldots \ldots \ldots \ldots \ldots \ldots \ldots \ldots \ldots \ldots . \ldots \ldots$

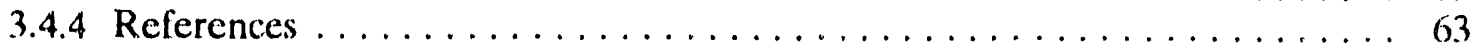

3.5 Elcctrical Hazards Are Controlled $\ldots \ldots \ldots \ldots \ldots \ldots \ldots \ldots \ldots \ldots$

3.5.1 Description $\ldots \ldots \ldots \ldots \ldots \ldots \ldots \ldots \ldots \ldots \ldots \ldots \ldots \ldots$

3.5 .2 Closure Requirements and Roadmap .................... $x_{6}$

3.5 .3 Related Technical Issues . . . . . . . . . . . . . . . . . . . 67

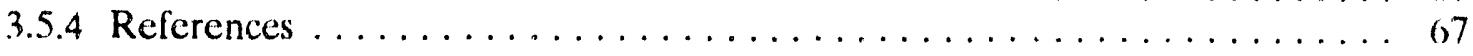

\section{FIGURES}

1. Roadmap for closure of the technical issue "Release characteristics are an acceptable risk to the environment"

2. Roadmap for closure of the technical issue "The degree and effects of metals pooling in the product are well characterized" $\ldots \ldots \ldots \ldots \ldots \ldots \ldots$

3. Roadmap for closure of the technical issue "The radiological characteristics of the product are acceptable"

4. Roadrnap for closure of the technical issue "The quantity of any waste that may he encapsulated (unprocessed) within the glass is acceptable" 


\section{TABLES}

1. Organization of technical issues for Volume $3 \ldots \ldots \ldots \ldots \ldots \ldots \ldots \ldots$

2. Technical issues and prioritics identified by the ISV Steering Committec and the section number within Volume 3 where the issue is addressed $\ldots \ldots \ldots \ldots \ldots 5$

3. Analytical procedures to be conducted for ISV product evaluation $\ldots \ldots \ldots \ldots \ldots$

4. Summary of data uses of the different data types $\ldots \ldots \ldots \ldots \ldots \ldots \ldots \ldots \ldots$ 


\section{ACRONYMS}

AA

ARARs

CERCLA

DOE

EDAX

EPA

EWR

HEPA

ICP

ICP-MS

ICPP

IFT

INEL

ISV

MCC

NEC

NFPA

OSHA

PCB

PNL

RCRA

RWMIS

STEM

SDA

SEM

TCLP atomic absorption

appropriate or relevant and applicable requirements

Comprehensive Environmental Response, Compensation, and Liability Act

Department of Energy

energy dispersive analysis by $\mathbf{x}$-ray

Environmental Protection Agency

early waste retrieval

high efficiency particulate air

inductively coupled plasma

inductively coupled plasma mass spectroscopy

Idaho Chemical Processing Plant

Intermediatc Field Test

Idaho National Engineering Laboratory

in situ vitrification

Materials Characteristic Center

National Electrical Code

National Fire Protection Agency

Occupational Safety and Health Administration

polychlorinated biphenyl

Pacific Northwest Laboratory

Resource Conservation and Recovery Act

Radioactive Waste Management Information Systcm

scanning transmitted electron microscopy

Subsurface Disposal Area

scanning electron microscope

toxicity characteristic leaching procedure 
TRU-PTs

XRD transuranic-contaminated waste pits and trenches $x$-ray diffraction 


\section{Technical Issues Associated with In Situ Vitrification of the INEL Subsurface \\ Disposal Area}

\section{Volume 3: Application of Technical Issues to the TRU-Contaninated Pits and Trenches}

\section{INTRODUCTION}

The in situ vitrification (ISV) technology may be considered a potential remedy for the Subsurface Disposal Area (SDA) transuranic-contaminated waste pits and trenches (TRU.PTs) at the Idaho National Engineering Laboratory (INEL). An ISV Steering Committec was formed in 1991 to help evaluate ISV technology for remediating the SDA. The purpose of the ISV Steering Committee was to define, prioritize, and develop roadmaps for closure of technical issues associated with the proposed application of ISV to the SDA. ${ }^{1}$

Determining technical issues confronting such an application of ISV depends upon waste configuration and composition in the pit. Since the most information was known about Pit 9, it was used as a general model for the possible contents in the other TRU-PTs. The contents of Pit 9 are the basis for the analysis of each technical issue; however, each issuc was written so as to be applicable to any other TRU-PTs.

A simulated TRU-PT pit was constructed to conduct an ISV field lest in 1990. The tests, using intermediate-scale test equipment, showed the viability of the ISV burici waste application. However, resolution of several issues must be addressed before the technology can be applicd as a remedy for buried waste.

\subsection{Background}

The SDA was established in 1952 for the disposal of waste generated at the INEL. Wastes were later received from a variety of other sources, including government agencies, universities, and research laboratories. From 1952 to 1970, wastes consisting of solid wastes, transuranic (TRU) contaminated wastes, and low-level wastes were buried in a series of pits and trenches at the SDA. These wastes were not rigorously segregated at the time of disposal, although TRU wastes were gencrally placed in pits and low-level wastes in trenches. ${ }^{2}$

TRU wastes were disposed of in Pits $1-6,9,10,11$, and 12 and in Trenches 1-10. Both trenches and pits were excavated to bedrock (10 to $20 \mathrm{ft}$ ) and then backfilled with a few feet of soil. Wastes were deposited in the pits and trenches in both a random and stacked lashion. Following waste placement, the pits and trenches were backfilled and covered with at least three feet of soil.

A varicly of wastes were disposed of in the pits and trenches. Wastes include organics, inorganics, toxic metals, and radionuclides. These wastes were contained in stecl drums, cardhoard cartons, and wooden boxes. Larger items were disposed of individually. 


\subsection{Site Characterization Studies}

Site characterization studies to date have focused on the available historic records from wiste disposal operations. Because of the heterogenous nature of the pits and trenches, physical sampling of the wasse matrix will be difficult. At this time, no sampling of the waste is planned. However, sub-pit and inter-pit sampling in the near future may provide additional and/or confirmation data to complement the historical records.

\subsection{TRU-PT Technical Issues}

To coordinate the resulution of technical issues related to ISV processing of buried waste, the ISV Stcering Committee identified technical issues related to ISV at the INEL. These issues are presented in the Technical Issues Associated with In Situ Vitrification of the INEL Subsurface Disposal Area, Volume 1: A Systematic Approach for Identification, Prioritization, and Closure of Technical Issues." Volume 2 addresses these technical issues for ISV application at the SDA Acid Pit. Volume 3 presents the technical issues organized in a manner different from that used in Volumes 1 and 2. This organization stems from the fact that many of the technical issues for the TRU-PTs required the same or a simila process for issue closure. Therefore, the issues are presented such that those that require the same or similar closure and roadmap are combined. The organization of the technical issues for Volume 3 is presented in Table 1.

The ISV Steering Committee prioritized the technical issues according to the criteria outlined in Volume 1. Table 2 lists each technical issue and its priority with the section number where it is discussed in this volume. Prioritization will facilitate the closure process by utilizing available rescrurces effectively, while striving to meet schedule, budget; and programmatic requirements. Prioritization also serves as a rational and technical basis for planning experimental and analytical programs supporting closure of these issues. Note that an issue's priority does not necessarily equate (1), kessen, or increase its importance.

This volume consists of closure roadmaps for each of the technical issues relevant to the TRU-PTs. In general " those roadmaps include

- Description

- Importance

- Influencing factors

- Suggested steps/requirements for issue closure

- References

The roadmaps address necessary actions required to obtain closure on the issue. The ISV technology will be evaluated using the Environmental Protection Agency (EPA) Comprehensive Environmental Response, Compensation, and Liability Act (CERCLA) evaluation criteria (sec: Volume 1). The roadmaps will provide the basic information required to complete the CERCLA evaluation.

\subsection{References}

1. C. M. Stomts et al., Technical Issues Associated with In Situ Virrification of the INEL Subsurface Disposal Area, Volume 1: A Systematic Approach for Identification, Proritization, and Closure of Techrical Issues, EGG.WTD.9985, Decemher 1991.

2. D. A. Arenholz et al., A Brief Analysis and Description of Transuranic Wastes in the Subsurface Disposal Area of the Radionctive Wiaste Management Complex at the INEL. EGG.WTD-94.38, Rev. 1. August 1991. 
Table 1. Organization of technical issues for Volume 3.

A. The durability/quality of product is acceptable.

1. Relcase characteristics of the product are an acceptable risk to the environment.

2. The homogeneity and other physical characteristics of the product are well characterized.

3. The degree and effects of metals pooling in the product are well characterized.

4. The radiological characteristics of the product are acceptable.

B. Subsurface contaminant migration during processing is within acceptable limits.

1. Any enhancements to subsurface contaminant migration provided by subsurface structures (pipes, drum surfaces, voids, etc.) are within acceptable limits.

2. Subsurface contaminant migration due to the effects of sealed containers is within acceptable limits.

3. Subsurface contaminant migration due to thermal gradients into surror nding homogencous soil is within acceptable limits.

C. Any rcsidual waste is acceptable. That is, the quantity of any waste left unprocessed in the soil is acceptable.

1. The melt width and depth are such that they capture the desired waste.

2. Mell channeling or preferential flow of the melt through the path of least resistance is predictable and does not impact the capture of the waste intended to be captured.

3. The quantity of any uncaptured waste between adjacent vitrificd blocks is acceptable.

4. The quantity of any waste that may be encapsulated (unprocessed) within the glass is acceptable.

D. Secondary waste streams (effluents from the offgas treatment system, scrub solutions, HEPA filters, decontamination solutions, etc.) are within acceptable limits.

E. The possibility of criticality is avoided.

F. Hood and Offgas Treatment System Seals Maintain Integrity.

1. Hood containment seals are adequate.

2. Any fires that may occur do not affect the integrity of the hood.

3. A sidewall collapse does not impact the seal between the hood skirt and the ground.

4. The melt and thermally altered zone do not extend laterally beyond the hood houndaries.

5. Offgas treatment system seals are adequate.

6. Underground fires are avoided. 
Table $\%$ (continued).

7. Any matter ejected from the melt is contained by the hood.

8. Any corrosion within the offgas treatment system does not affect containment of effluents.

G. Hood and Offgas System Handle Pressure Transients

1. Pressurizations duc to explosions remain contained by the hood.

2. Pressurizations due to the breach of pressurized sealed containers remain contained by the hood.

3. Sudden increases in offgas due to waste falling from the sidewall onto the melt surface remain contained by the hood.

4. Increases in offgas due to the melt encountering voids remain contained by the hood.

5. Offgas generation caused by combustion within the hood is contained by the hood.

6. Pressurizations due to explosions remain contained within the offgas treatment system.

7. Increases in offgas due to the breach of pressurized sealed containers are contained and processed adequately within the offgas treatment system.

8. Sudden increases in offgas due to waste falling from the sidewall onto the melt surface are contained and processed adequately within the oflgas treatment system.

9. Increases in offgas due to the melt encountering voids is contained and processed adequately within the offgas treatment system.

10. Excessive offgas generation caused by combustion is contained within the offgas treatment system.

H. Risks duc to exposed wastc.

1. Risks duc to any exposed waste are within acceptable limits.

2. Post-processing hood containment is maintained as required.

3. Offgas treatment system capacity for treatment of products from within the hood is adequate.

I. Electrical hazards are controlled. 
Table 2. Technical issues and priorities identified by the ISV Steering Committec and the section number within Volume 3 where the issue is addressed.

A. The durability/quality of product is acceptable.

1. Release characteristics of the product are an acceptab.e risk, to the environment (Priority: 10, Section 2.1).

2. The product is well characterized.

a. The homogeneity and other physical characteristics of the product are well characterized (Priority: 29, Section 2.1).

b. The degree and effects of metals pooling in the product are well characterized (Priority: 27, Section 2.1).

3. The radiological characteristics of the product are acceptable (Priority: 30, Section 2.1).

B. Subsurface contaminant migration during processing is within acceptable limits.

1. Any enhancements to subsurface contaminant migration provided by subsurface structures (pipes, drum surfaces, voids, etc.) are within acceptable limits (Priority: 14, Section 2.2).

2. Subsurface contaminant migration due to the effects of sealed containers is within acceptable limits (Priority: 15, Section 2.2).

3. Subsurface contaminant migration due to thermal gradients into surrounding homogeneous soil is within acceptable limits (Priority: 18, Section 2.2).

C. Any residual waste is acceptable. That is, the quantity of any waste left unprocessed in the soil is acceptable.

1. The melt shape is predictable and suitable for capturing the waste intended to be captured.

a. The melt width and depth are such that they capture the desired waste (Priority: 8 , Section 2.3).

b. Melt channeling or preferential flow of the melt through the fath of least resistance is predictable and does not impact the capture of the waste it nded to be captured (Priority: 9, Section 2.3).

c. The quantity of any uncaptured waste between adjacent vitrified blocks is acceptable (Priority: 5, Section 2.3).

2. The quantity of any waste that may be encapsulated (unprocessed) within the glass is acceptable (Priority: 33 , Section 2.3 ).

D. Secondary waste streams (effluents from the offgas treatment system, scrub solutions, HEPA filters, decontamination solutions, etc.) are within acceptable limits (Priority: 7, Section 2.4).

E. The possibility of criticality is avoided (Priority: 1, Section 3.1). 
Table 2. (continued).

F. Hazardous/radioactive material is adequately contained by the equipment.

1. Hazardous/radioactive material is adequately contained by the hood.

a. Hood containment seals are adequate (Priority: 20, Section 3.2).

b. Any fires that may occur do not affect the integriiy of the hood (Priority: 23, Section 3.2).

c. The hood covers adequate ground area to prevent releases.

(1) A sidewall collapse does not impact the seal between the hood skirt and the ground (Priority: 25, Section 3.2).

(2) The melt and thermally altered zone do not extend laterally beyond the hood boundaries (Priority: 32, Section 3.2).

d. The hood handles pressure transients adequately.

(1) Pressurizations due to explosions remain contained (Priority: 13, Section 3.3).

(2) Pressurizations due to the breach of pressurized scaled containers remain contained (Priority: 4, Section 3.3).

(3) Sudden increases in offgas due to waste falling from the sidewall onto the melt surface remain contained (Priority: 28 , Section 3.3 ).

(4) Increases in offgas due to the melt encountering voids remain contained (Priority: 21, Section 3.3).

(5) Offgas generation caused by combustion within the hood is contained (Priority: 3, Section 3.3).

e. Any matter ejected from the melt is contained by the hood (Priority: 12 , Section 3.2).

2. The offgas treatment system provides adequate containment and maintains effluents to acceptable levels.

a. Offgas treatment system seals are adequate (Priority: 31, Section 3.2).

b. Offgas treatment system capacity for treatment of pr oducts from within the hood is adequate (Priority: 6, Section 3.4).

c. The offgas treatment system handles pressure transients adequatcly.

(1) Pressurizations due to explosions remain contained (Priority: 17, Section 3.3).

(2) Increases in offgas due to the breach of pressurized sealed containers are contained and processed adequately (Priority: 2. Section 3.3). 
Table 2. (continued).

(3) Sudden increases in offgas due to waste falling from the sidewall onto the melt surface are contained and processed adequately (Priority: 22, Section 3.3).

(4) Increases in offgas due to the melt encountering voids are contained and processed adequately (Priority: 23, Section 3.3).

(5) Excessive offgas generation carsed by combustion is contained (Priority: 11 , Section 3.3).

d. Any corrosion within the offgas treatment system does not affect containment of effluents (Priority: 34, Section 3.2).

3. Risks due to any exposed waste are within acceptable limits (Priority: 19, Section 3.4).

4. Post-processing hood containment is maintained as required (Priority: 16, Section 3.4).

G. Underground fires are avoided (Priority: 26, Section 3.2).

H. Electrical hazards are controlled (Priority: 35, Section 3.5). 


\section{ENVIRONMENTAL ISSUES}

\subsection{Durability/Quality of the Product is Acceptable}

\subsubsection{Description}

2.1.1.1 Description of the issue. The primary purpose of the ISV process is to stabilize, immobilize, and reduce the volume of radioactive and hazardous waste components. Therefore, it is important to know accurately the durability and quality characteristics of the ISV product. Data concerning the release and radiological characteristics of the ISV product are necessary in the treatability study for evaluation in the Remedial Investigation/Feasibility Study (RI/FS) process to show that the product is an acceptable risk to human health and the environment. Criteria for evaluation of the ISV product include meeting regulatory requirements, comparison with other similar ISV products, and comparison with natural analogs. Other product characterization data such as homogencity, susceptibility to fracture, and metal pooling are important for fundamental knowledge of the ISV process, as well as for infornation for the public to know what is at a waste site once remediation is completed.

This issue addresses the following technical issues:

- The release characteristics are an acceptable risk to the environment

- The homogeneity and other physical properties of the product are well characterized

- The degree and affects of metals pooling in the product are well characterized

- The radiological properties of the product are acceptable.

2.1.1.1.1 Release Characteristics-This technical issue addresses the durability (release or dissolution characteristics) of the ISV product produced by the ISV process to determine its ability to immobilize hazardous and radioactive waste components. The composition of the melt product is the primary factor in making an assessment of release characteristics of the product; therefore, it is important to properly characterize the TRU.PTs to address this issue.

2.1.1.1.2 Homogeneity and Other Physical Properties Are Well Characterized-The ISV glass-like product may devitrify to crystalline material, resulting in an inhomogeneous product. This is due to the slow thermal diffusion, long cooling times, and elemental components of the product. Surface effects will also affect the morphology of the product. By identifying the major regions of the product, with stratified random sampling of those regions, sufficient data can be generated to determine the chemical, morphological, and durability properties of each region. This megascopic description of the product is important because the sampling strategy for all other characterization data needed cannot be detailed until the type and distribution of the major regions are known. The megascopic evaluation is also important in determining the percent volume that each region represents out of the total product volume. This information is required to allow for a bulk mass balance, an identification of potential reactions at regional interfaces, and the determination of an overall source term (the quantity of material available for release to the environment) for release rate and durability. The structure and elemental composition of each crystalline phase will reveal if any waste components have segregated into a less durable phase.

2.1.1.1.3 Metals Pooling-In wastes where large amounts (approximately $>4 \mathrm{wt} \%$ ) if metals are present, possibly as contaminated metal objects, metal drums used as disposal containcrs, metallic hazardous waste components, etc., there is the potential for metais to separate from the melt and form a metal pool at the bottom of the melt. As the melt interacts with these metals, some of the metals (depending on the type and total amounts) dissolve into the glass matrix until the glass 
becomes saturated. This generally requires the metals to oxidize with other compounds, forming metal oxides that are more soluble in the melt. Once the melt solution becomes saturated with metal cations, the denser metal compounds amass and sink to the bottom of the melt, forming a metal pool at the bottom of the melt. Metal pools can also form within the melt due to redox reactions with the cations in the melt and the graphite electrodes. Redox states within previous melts have had $\mathrm{Fe}^{+2} / \mathrm{total} \mathrm{Fe}$ ratios of approximately 0.8 to 0.95 (very reducing). The metal pool can also be formed by a metal object being partially melted and dropping to the bottom of the melt due to the higher density and encountering lower melt front temperature, slowing the reaction with the melt. These reactions and the formation of some metal pools have been observed in laboratory and field tests cvaluating $P$ it 9 waste and soils. $1,2,3$

2.1.1.1.4 Radiologica/ Characteristics-The radiological acceptability of the ISV product is gencrally based on the radioactive dose given off and the concentration of radionuclides within the waste. During the ISV process, the waste undergoes radical physical changes in structure, volume, density, and component distribution. These changes could alter the radiological characteristics of the ISV product to the point where the waste classification of the product would change or handling requirements (as in the case of retrieval) would change.

The ISV processing of buried waste in SDA soil results in an overall volume reduction of approximately $50-65 \%$. When radionuclides are present, volume reduction increases their concentration (measured as nanocuries/cubic meter). This may result in an increase in the amount of radiation at the surface of the product (millirems/hour). However, emanation of radioactivity from existing ISV products is low.

Because the ISV process incorporates additional material (as soil) into the waste, the radionuclide concentration measured as nanocuries/gram decreases. However, waste component scgregation potentially could concentrate some radionuclides into locally higher concentrations, such as in the case of metal pooling.

\subsubsection{Importance.}

2.1.1.2.1 Release Characteristics-Since the primary purpose of the ISV process is to stabilize and immobilize radioactive and hazardous waste components, release characteristics of ISV waste forms must be known to provide for an accurate performance assessment. Failure to adequately bound the release characteristics of ISV waste forms from laboratory and field tests does not allow for the required data to be presented in the treatability study evaluating ISV in the Remedial Investigation/Feasibility Study (RI/FS) process. Release data is also required for input to the health-based risk assessment that is part of the RI/FS process. Furthermore, it must be shown that any demonstrations of ISV will not adversely affect the migration of hazardous and radioactive contaminants in the soil. Waste and soil composition are of prime importance with respect to product durability. All major phases within the ISV monolith must be evaluated.

There are a number of significantly different types of waste buried within the TRU-PTs. In addition there can be a wide range in the composition makeup even for a given waste type. This results in wide extremes in the composition envelope of waste. In addition, the amount of soil as overburden, underburden, and in the interstitial volume of the waste will also vary. Because the melt composition is the primary factor in the durability and ability to immobilize waste components in the ISV waste product, these variations must be addressed.

\subsection{Homogeneity and Other Physical Characteristics Are Well} Characterized-The ultimate goal of ISV as a remedial technology is to produce a durable product that will inmobilize radioactive and/or hazardous constituents at a waste site. If the product devitrifies into several crystalline phases, or if the product has several distinct regions having different 
chemical and physical properties, the overall product may not meet the durability needs of ISV. Thus, it is important to know the physical characteristics and homogeneity of the product to determine its durability and quality.

2.1.1.2.3 Metals Pooling-As the molten metals and dissolving metal objects coalesced in the bottom of the melt, the metals may be immiscible or may alloy with different metals. This results in a heterogeneous pool of metals and slags that may contain hazardous and/or radioactive waste components. This metal pool portion of the waste form may have unacceptable release and durability characteristics. The characterization of the degree and affects of metal pooling must be known to provide an accurate assessment of the risk associated with leaving the waste form in place.

2.1.1.2.4 Radiological Characteristics-The relatively small amount of radioactive components in the TRU-PTs will be soluble in the melt. ${ }^{4,5,6,7,8,9}$ This would result a redistribution of the radionuclides into the melt. These changes could alter the radiological characteristics of the ISV product to the point where the waste classification of the product would change (possible changing disposal requirements). Handling requirements could also change, making retrieval requirements more or less restrictive.

\subsubsection{Influencing Factors.}

2.1.1.3.1 Release Characteristics-Factors influencing the release characteristics of the product are the type, composition, and amount of contaminates in the TRU-PTs, and the type, composition, and amount of soil in the overburden, underburden, and interstitial volume of the TRU-PTs. Of particular interest is the soil-to-waste ratio and the amount of alkalis present in the TRU-PTs, since a high alkali content may result in poor product durability.

2.1.1.3.2 Homogeneity and Other Physical Properties Are Well Characterized, Metals Pooling, and Radiological Characteristics-The composition of the soil and its buricd waste will have a direct affect on the homogeneity and physical characteristics of the product. Waste that contains significant amounts of metals has the potential for metals to separate from the melt and pool at the bottom of the melt, resulting in a product having unacceptable release rates and durability characteristics. The TRU-PTs are known to contain large amounts of metal in the form of empty contaminated drums, contaminated metal scraps, and other metal objects. Also, the reducing nature of the graphite electrodes with organic content of the pit may cause certain metal oxides to reduce to metallic states and pool at the melt bottom. The type of metal will impact the composition and morphology of the metal pool and the waste components that may be retained within the metal pool.

Melts that encounter sizeable voids may cause the sidewalls next to the melt to collapse onto the melt. Major sidewall collapses occurring toward the end of the ISV process may not get sufficiently incorporated into the melt, resulting in an inhomogeneous product that may have less durable physical properties.

Certain soil or waste properties can affect the formation of an acceptable product. For example. during initial scoping tests, it was found that the soil crystallized rather than vitrified with $\mathrm{Na}_{2} \mathrm{O}$ concentrations in excess of $35-40$ percent weight, even under rapid cooling conditions. ${ }^{10}$ By modifying the soil composition with soil additives, such as by adding a determined amount of $\mathrm{CaO}$ or soil, undesirable soil/waste properties may be adjusted to suit ISV application at the TRU-PTs.

Similar to metal pooling, waste that contains significant amounts of radioactive compounds could amass in one area of the melt product, generating undesirable or unacceptable levels of radioactivity from the final meit product. However, it is assumed that the amount of radioactive components in the TRU.PT is small enough to be soluble in the melt. In addition, there is a strong tendency for the TRU elements to become incorporated in the melt instead of the molten metal phase. $4,5,6,7, x, 9$ 
The rate of cooling may result in the product having inhornogeneous regions. Just as obsidian is formed when volcanic lava loses heat too quickly to permit crystallization, the ISV glass product is formed as the melted soil cools. A long cooling time will allow parts of the glass product to devitrify into crystalline phases. Because the ISV glass product is similar to obsidian or rhyolite (devitrified obsidian) in composition and weathering characteristics (durability), it should have similar durability characteristics. Leach resistance studies on nonradioactive vitrified soil that contained large fractions of crystalline products have indicted that the crystalline phases are not detrimental to overall leach resistance. ${ }^{3,10}$

\subsubsection{Closure Requirements and Roadmap}

2.1.2.1 Assumptions. There are a significant amount of metals in the TRU-PTs due to the metal drums, metal objects, and transition metal oxides.

It is assumed that the TRU material in the TRU-PT was disposed of in a manner such that a critical or near-critical condition does not exist prior to ISV processing of the wastc.

\subsubsection{Requirements and Steps to Close Issue.}

2.1.2.2.1 Relezse Characteristics-To make a proper decision about the suitalility of the ISV process for remediation of the TRU-PTs and to address the appropriate portions of the EPA CERCLA criteria, the following technical questions must be answered:

- Does the ISV product meet regulatory requirements [e.g., toxicity characteristic leaching procedure (TCLP)] ${ }^{11}$

- How does the ISV product compare (solubility and release) with other similar waste products?

- How does the ISV product compare (solubility and release) with natural analogs?

- What are the source terms for waste component release in the ISV product? (This will be a requirement for the health-based risk assessment modeling activities.)

There are currently no specific durability specifications established for ISV products. The minimum expected testing requirements will be those currently established for landfill disposal. One of those requirements is the TCLP test. However, the TCLP does not (a) address radioactive waste components, (b) provide a technical basis for assessing long-term durability, (c) provide a basis for a comparison to highly durable products or natural analogs, or (d) provide an assessment of the source-term release rate of the waste component for risk assessment models. Therefore, additional durability tests must be conducted. These additional tests fall into two categories, comparative testing (comparing ISV products to similar waste forms and natural analogs) and testing to determine the intrinsic rate of the product dissolution $\left(\mathbf{k}_{+}\right)$. Each category of durability testing is discussed in detail in the following subsections. For each type of test, all major phases within the ISV product should be included, if possible. Where multiple phases cannot be separated, such as when devitrification produces an intimate mixture of different small-grain crystalline phases, these phase mixtures should be tested as a single phase. Where possible, tests should be conducted at the largest scale possible. Laboratory-scale tests should be the minimum when testing the durability of the waste form.

A roadmap outlining the steps to closure for the release characteristics issue is given in Figure 1.

\subsection{Regulatory Required Tests (TCLP)-}

One of the requirements for determining if waste is hazardous is the TCLP test. Waste is hazardous if it meets the criteria for the definition of hazardous waste, cited in the Code of Federal 


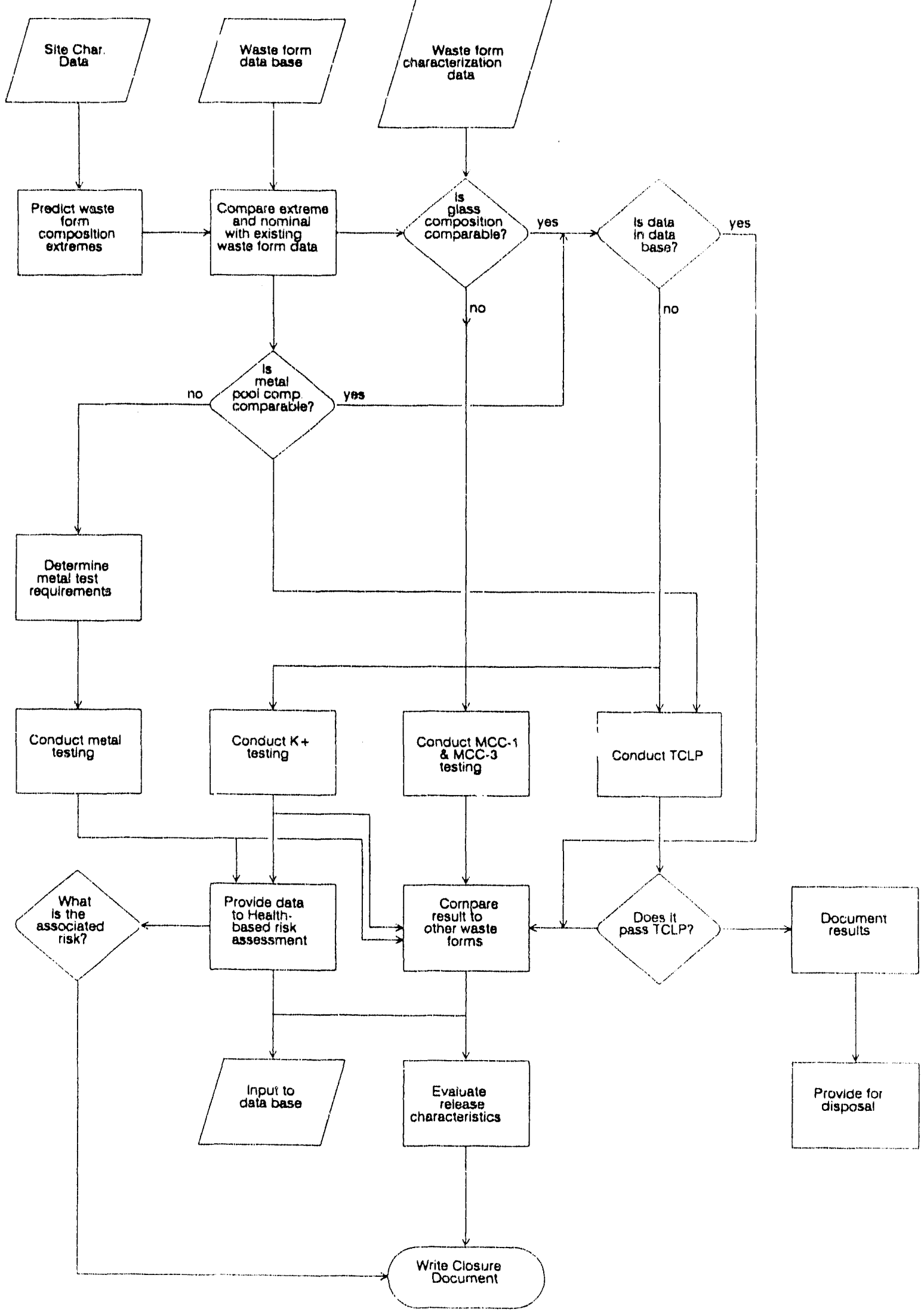

Figure 1. Roadmap for closure of the technical issue "Release characteristics are an acceptable risk to the environment." 
Regulations 40 CFR 261.3. ${ }^{12}$ This definition includes criteria for ignitability, reactivity, corrosiveness, and TCLP toxicity. After being formed at temperatures greater than $1,300^{\circ} \mathrm{C}$, the ISV products are neither ignitable, reactive, nor corrosive. The TCLP test is designed to simulate the leaching process waste undergoes if disposed of in a sanitary landfill. Accordingly, the ISV product will need to be tested for TCLP. However, since hazardous organic compounds are destroyed by the extreme processing temperatures through pyrolysis, the organic analysis portion of TCLP will not be necessary.

\subsection{Comparative Tosting-}

To provide a scientific basis for evaluating the short- and long-term durability of ISV products, additional testing will be required. While the TCLP test satisfies compliance with EPA requirements for hazardous waste disposal, these tests have little value in quantifying the release characteristics of the ISV product. The resulting product from the ISV process is similar to a number of natural analogs and to the waste forms evaluated for high-level nuclear waste. By comparing test a csults for ISV products to other well-documented products and natural analogs, a baseline can be established for comparing the durability of the ISV product.

Assessing the long-term durability of ISV product is difficult because it requires extrapolation of data from short-term laboratory tests (a few hours to a few years) to geologic time frames. One way to assess the long-term durability performance is to compare the ISV prodict with natural analogs. A number of natural analogs are similar in composition and morphology to the ISV products. These include obsikian, basalts, tektites, and andesites (all of which can be millions of years old). The relative durability of mainy natural and ancient manmade glasses have been shown to bracket the durability of waste glasses. ${ }^{13,14,15,16}$ Thus, relating the behavior of the ISV products determined from short-term leach test and modeling results with the observed behavior of natural analogs provides an excellent means of validating the long-term stabiiity of the ISV product.

Natural analogs also provide a basis for assisting in public acceptance of the ISV process and product. While the public has little understanding of the durability of high-level waste glasses, they may have appreciation for a comparisen made of the ISV product to a "rock" they can pick up in the field that has been exposed to the environment for perhaps millions of years (geologic times).

The Materials Characteristic Center's (MCC) MCC-1 and MCC-3 test methods and current procedures were originally developed and written for application to high-level waste repositories in deep geological environments. ${ }^{17,18}$ A specific set of MCC-3 test conditions is now being used as the a standard test for high-level waste glasses, called the Product Consistency Test (PCT). ${ }^{19}$ The primary applications of the MCC tests will be to compare ISV products with information from existing data bases and will have limited use for mass transport analysis. By conducting the MCC-1 and PCT leach testing at $90^{\circ} \mathrm{C}$, the results can be compared to the existing large database of leaching data on the high-level glasses. One drawback to the MCC-1 procedure is that it requires a small monolithic sample. Inhomogeneities in the test samples, such as varying amounts of exposed crystalline phases or metals, may result in inconsistent results. If possible, MCC-1 testing should be conducted with single phase samples. "The PCT is similar to the MCC-1 test procedure, with two exceptions: the glass sample is ground to a powder, and glass powder and leachant are agitated by rotating the Teflon container in which the sample is placed. The elemental leachate concentrations from PCT tests are estimated to represent long-term extrapolation of MCC-1 test results (from increased saturation of the leachates). This objective is achieved more rapidly in the PCT test because higher ratios of glass surface areas/leachate volumes (SA/V) are used than those used for the MCC-1 tests $\left(2000 \mathrm{~m}^{-1}\right.$ and $10 \mathrm{~m}^{-1}$, respectively). Because a powdered sample is used for the PCT tests, combinations of glass and devitrified phases may be tested together. 


\subsection{Intrinsic Rate of Dissolution $\left(k_{+}\right)-$}

The fastest rate at which a glass/ceramic will dissolve is the intrinsic rate of dissolution $\left(\mathrm{k}_{+}\right)$. This glass parameter has the most technical relevance when evaluating and predicting the dissolution (durability) behavior of the glass. The intrinsic rate will be used as the source term in health-based risk assessment models to determine the risk associated with leaving the ISV product in the ground. This will be a conservative value for the source term as saturated or partially saturated groundwater will slow the dissolution of the product significantly. A detailed discussion of intrinsic ratc is presented in other documents. ${ }^{20,21,22,23}$

The intrinsic rate of dissolution $\left(k_{+}\right)$is measured by multiplying $S A / V$ values by time. A low $k_{+}$value means that the rate at which a glass/ceramic dissolves is very slow and that the resulting concentration of the dissolution solution is $\mathrm{kw}$. Low $\mathrm{k}_{+}$values are expected for the ISV product at normal, ambient conditions. Ambient conditions at the SDA are semiarid and the average annual precipitation at the INEL is 8.5 inches. ${ }^{24}$ Saturation of the I'SV product is not expected due to the relatively dry climate and the measures taken at the SDA to prevent flooding, direct surface water runoff, reduce water infiltration, and reduce soil erosion. Thus, the intrinsic rate of dissolution will be the limiting factor in the release rates of contaminants. In addition, because $k_{+}$represents the absolute maximum dissolution rate, a conservative source term (the quantity of material available for release to the human environment during normal conditions or accidents) can be derived from an accurate determination of this parameter. This source term can be used in health-based risk assessment modi ling.

Many chemical reaction rates, including $k_{+}$, increase with temperature. Because of the high durability of the ISV product, it may not be possible to conduct leach testing at ambient ground temperatures (less than or equal to $20^{\circ} \mathrm{C}$ ) because the resulting leachate concentrations may be below analytical detection limits. Conducting leach testing at higher temperatures (approximately $40-90^{\circ} \mathrm{C}$ ) will provide more detectable leachate concentrations. If leachates are lested at two or more temperatures, the Arrhenuis activation energy of $\mathbf{k}_{+}$can be determined, from which the temperature dependence can be established. Using this temperature dependence, $k_{+}$at ambient storage conditions can be calculated.

2.1.2.2.2 Homogeneity and Other Physical Characteristics Are Well Characterized-The primary objective of the product evaluation sampling activities of the laboratory and field tests are to provide representative samples in sufficient number and quantity that provide a general description of the ISV monolith and detailed evaluation of the properties of the different phases observed. Sampling will be conducted using cores drilled through the monolith and/or a fracture of the monolith. A megascopic, bulk, physical description of an ISV product is the necessary first step in the characterization of that material. The megascopic description provides the most general information gained during the material characterization processes. It is a narrative and photographic record of the type and distribution of those regions that can be distinguished and defined by the unaided eye.

Previous ISV tests conducted at other sites indicate that there are generally five distinct regions within a typical ISV product that should be evaluated: (a) the vitreous frothy surface layer, (b) the partially reacted "rind" layer, which marks the vitrification surface of the monolith, (c) the glass material, (d) the crystalline devitrified material near the center of the monolith, and (e) the potential "pools" or segregation of metals at the electrodes or at the bottom of the monolith.

A megascopic description of the monolith is important because the sampling strategy of all other characterization techniques cannot be detailed until the type and distribution of the megascopic regions are known. A random sampling of the whole monolith may fail to sample each region sufficiently. By identifying the major regions of the monolith, with stratified random sampling of those regions, sufficient data can be generated to determine the chemical, morphological, and durability properties of each region. The megascopic evaluation will also assess the volume 
percentage of the total that each region represents. This information is required to allow for a bulk mass balance, an identification of potential reactions at regional interfaces, and a determination of a bulk durability (release) source term. Additional samples will be taken and archived. This will allow for further testing if regulatory requirements change or additional data are required.

Evaluating the chemical and morphological properties is necessary to detcrmine the elemental composition of the ISV product as a whole, by region, and of each phase in the region. Because of the many elemental components, the thermal diffusion of the glass, and the long cooling times of the monolith, some of the glass will devitrify to crystalline material. The structure and elemental composition of each crystalline phase will reveal if any waste components have segregated into possibly less-durable phases or migrated to interface boundaries between the metal, glass, and crystalline phases.

Several techniques will be used for this portion of the evaluation. Inductively coupled plasma (ICP) atomic emission spectroscopy will be used to determine the overall elemental composition of each region and phase. The ICP will also provide the elemental composition to be used to determine normalized release in the durability tests. While ICP will be the main elemental analytical technique, other analytical techniques will be used to augment ICP for specific elements and data drive needs. These techniques include ICP-mass spectroscopy (ICP-MS), atomic absorption (AA), and scanning transmitted electron microscopy (STEM).

A scanning electron microscope with energy dispersive analysis by an $x$-ray (SEM/EDAX) microprobe will be used to observe the crystalline types present. Elemental mapping of SEM scans and EDAX microprobe analysis will indicate the semiquantitive elemental makeup of each phase. This will indicate if any detectable segregation of waste components has occurred. Particular attention will be given to the interface boundaries between the metal, glass and crystalline phases. The SEM will also provide micrographs for image analysis and determination of the percent of crystalline material.

X-ray diffraction (XRD) will be used to identify the structure of the crystalline material. When used in conjunction with the SEM/EDAX data, the specific crystalline phases that result from devitrification near the center of the monolith can be determined. Knowledge of the crystalline morphology will help determine how waste components are incorporated into the ISV product, allow for comparison to natural analogs, and assist in assessing long-term behavior of the waste (e.g., geochemical solution and reaction path modeling).

The redox state of the ISV product should also be determined. This will provide an indication as to the valence state expected for waste components and will help predict in which phase waste components will be partitioned within the ISV product. For example, if conditions within the ISV melt are sufficiently reducing, elements such as chromium, lead, or cadmium may be present in the metallic state. If in the metallic state, metals may combine with other metals within the melt and partition to the bottom of the ISV product. The redox state will be determined by analyzing the $\mathrm{Fe}^{+2} / \mathrm{total} \mathrm{Fe}$ ratio in the glass using a compleximetric, spectro-photometric technique. ${ }^{25}$

A summary of the analytical procedures and their output data is presented in Table 3 . A summary of the data uses of the different data types is presented in Table 4.

2.1.2.2.3 Metals Pooling-Figure 2 presents a roadmap outlining the steps for closure of the metals pooling issue.

2.1.2.2.4 Radiological Characteristics-The roadmap for closure of this issue in presented in Figure 3. This issue can be closed with calculations and little or no experimental work outside that required in the related technical issues. 
Table 3. Analytical procedures to be conducted for ISV product evaluation.

\begin{tabular}{ll}
\hline \multicolumn{1}{c}{ Analytical Procedure } & \multicolumn{1}{c}{ Variable/Paramcter } \\
\hline $\begin{array}{l}\text { Scanning electron microscopy with } \\
\text { energy dispersive analysis by X-ray, }\end{array}$ & Waste component segregation, elemental map- \\
microprobe (SEM/EDAX) & ping, input to image anal., phase identification, \\
X-ray diffraction (XRD) & Phase identification, phase \%ol \\
Density & Specific gravity \\
Image analysis & phase \%vol \\
Optical analysis & Sampling and test requirements, phase identifi- \\
& cation, phase \%vol \\
Inductively coupled plasma atomic & Elemental analysis \\
emission spectroscopy (ICP) and & \\
atomic absorption (AA) & \\
Radionuclide analysis & Radionuclide contcnt \\
Redox state & Fe+2/ 2 Fe (oxidation state of waste form) \\
\hline
\end{tabular}




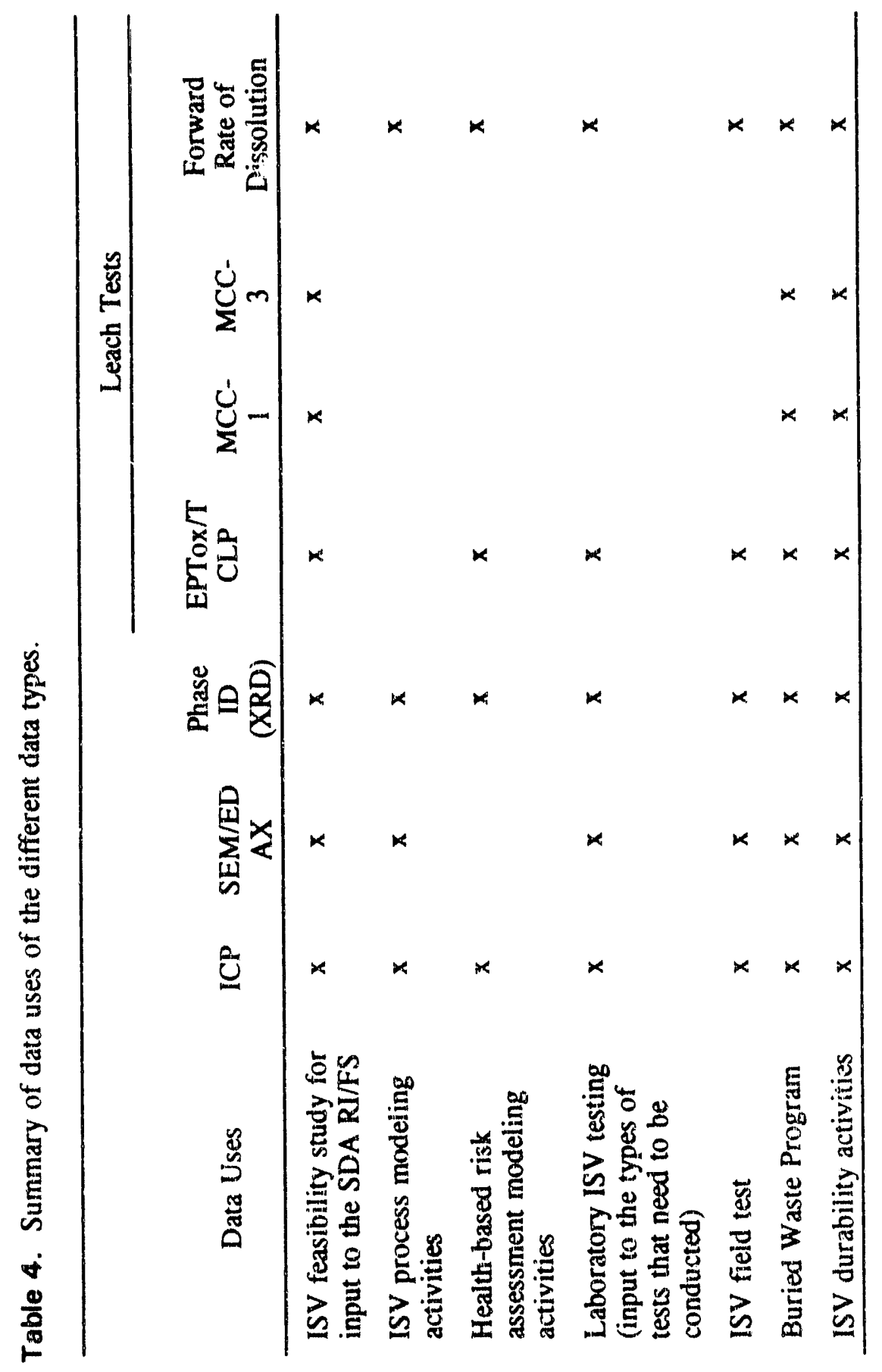




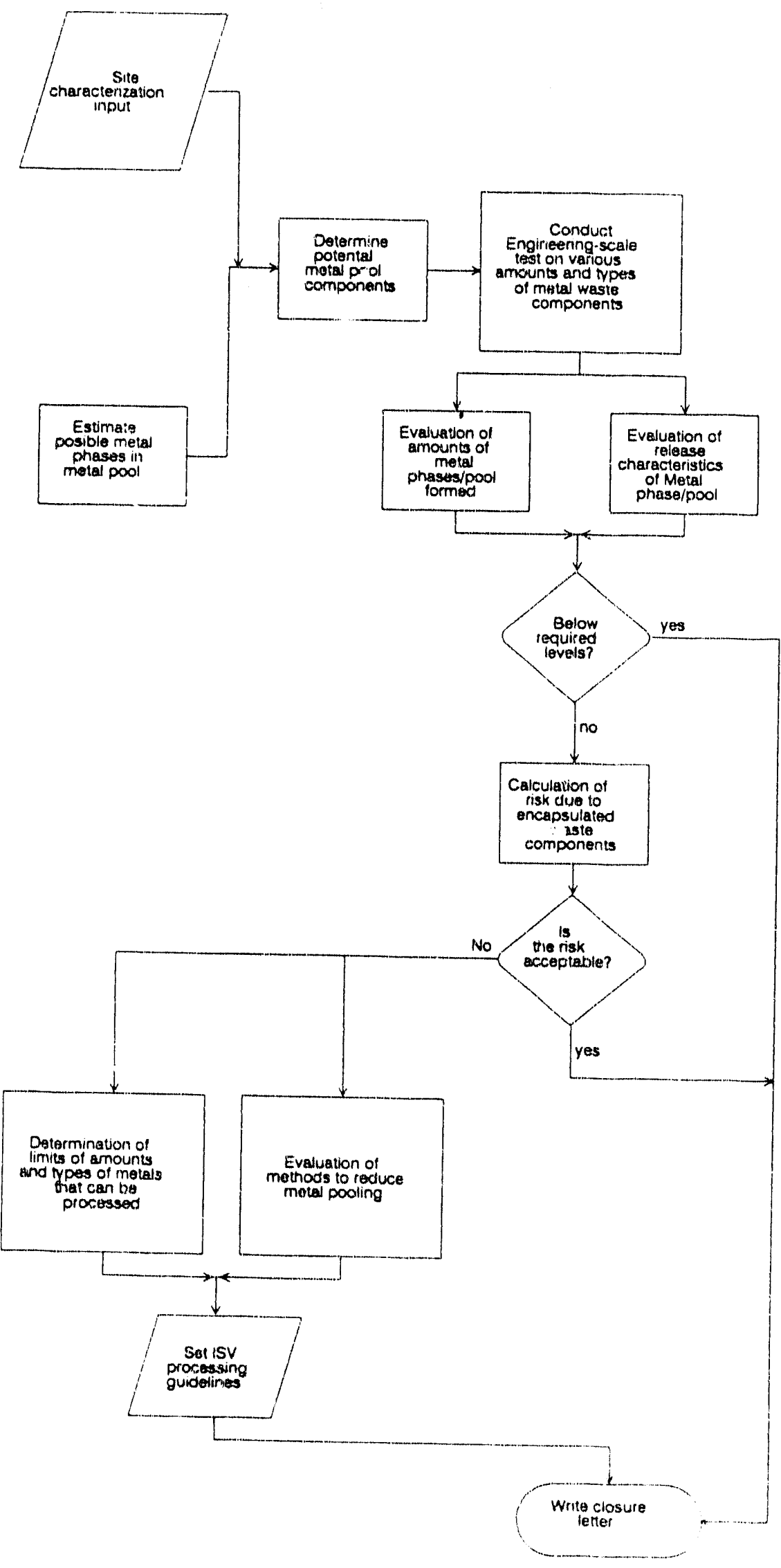

Figure 2. Roadmap for closure of the technical issue "The degree and effects of metals pooling in the product are well characterized." 


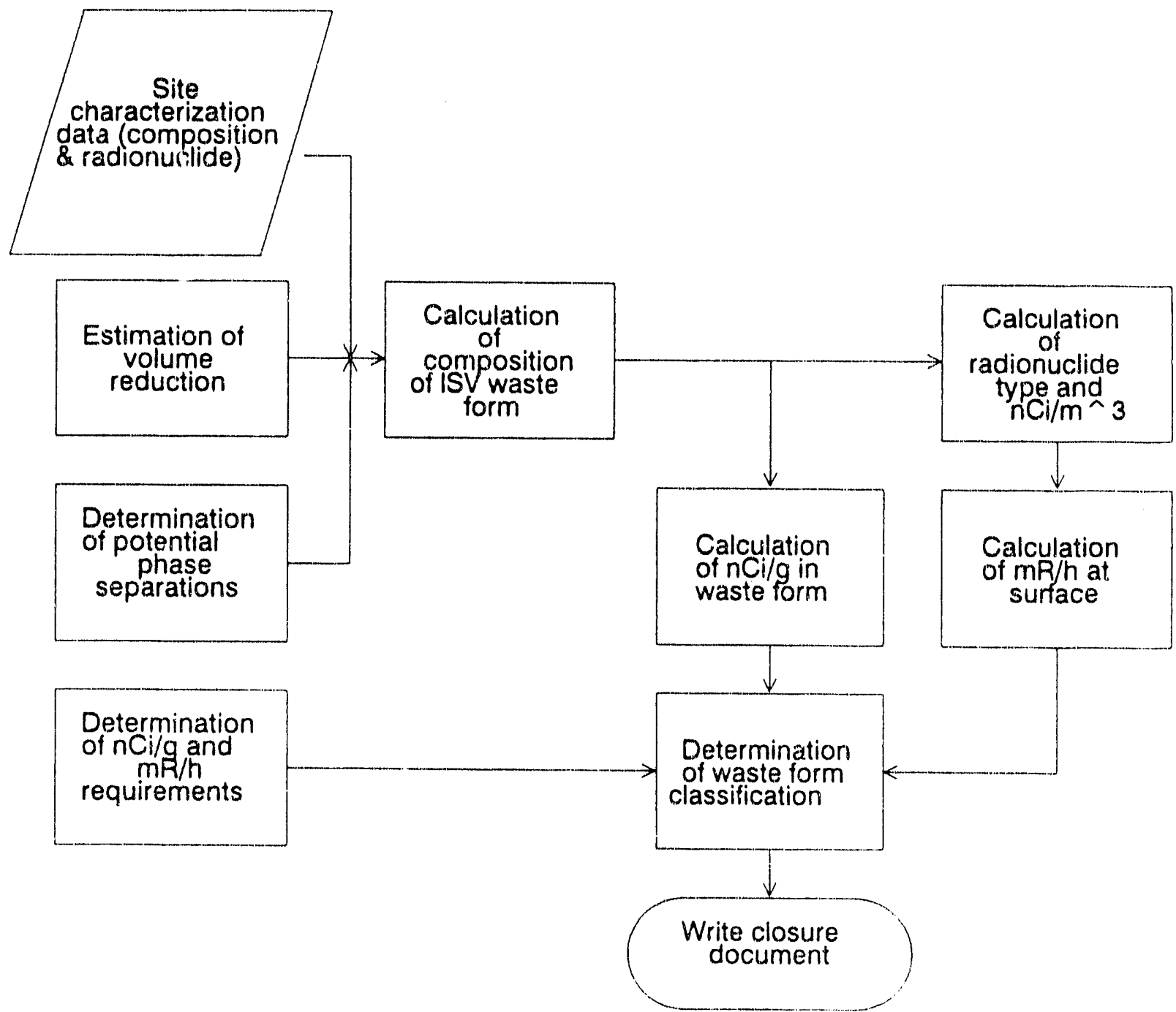

Figure 3. Roadmap for closure of the technical issue "The radiological characteristics of the product are acceptable." 


\subsubsection{Related Technical Issues}

3.1 The possibility of criticality is avoided.

\subsubsection{References}

1. R. K. Farnsworth, K. H. Oma, and M. A. H. Reimus, Crucible Melts and Bench-Scale ISV Test on Simulated Wastes in INEL Soils, PNL-7344, Pacific Northwest Laboratory, Richland, Washington, 1990.

2. R. A. Callow, L. E. Thompson, and J. R. Weidner, In Situ Vitrification Application to Buried Waste: Interim Report of Intermediate Field Tests at the Idaho National Engineering Laboratory, EGG-WTD-9422, EG\&G Idaho, Inc., Idaho Falls, Idaho, 1991.

3. R. A. Callow, L. E. Thompson, J. R. Weidner, C. A. Loehr, B. P. McGrail, and S. O. Bates, In Situ Vitrification Application to Buried Waste: Final Report of Intermediate Field Tests at the Idaho National Engineering Laboratory, EGG-WTD-9807, EG\&G Idaho, Inc., Idaho Falls, Idaho, 1991.

4. N. Levitz et al., "Volume Reduction and Salvage Considerations for Plutonium-Contaminated Ferrous Metals," AIChE Symposium Series, 72, No. 154, 1976, pp. 86-89.

5. M. G Seitz, T. J. Gerding, and M. J. Steindler, Decontamination of Metals Containing Plutonium and Americium, DOE Report ANL-78-13, June 1979.

6. G. L. Copeland, R. L. Heestand, and R. S. Mateer, Volume Reduction of Low-Level Contaminated Metal Waste by Melting - Selection of Method and Conceptual Plan, DOE Report ORNL/TM-6388, June 1978.

7. B. Heshmatpour and G. L. Copeland, The Effects of Slag Composition and Process Variables on Decontamination of Mctallic Wastes by Melt Refining, DOE Report ORNL/TM-7501, January 1981.

8. B. Heshmatpour, G. L. Copeland, and R. L. Heestand, Decontamination of Transuranic Waste Metal by Melt Refining, ORNL/TM 7951, Oak Ridge National Laboratory, Oak Ridge, TN, 1981.

9. C. W. Hobbick, D. R. Schatz, and G. D. Aden, Distribution and Removal of Radionuclides in Molten Stainless Steel, DOE Report RHO-CD-1444, 1981.

10. J. L. Buelt, V. F. FitzPatrick, C. L. Timmerman, J. G. Carter, and K. H. Oma, In Situ Vitrification of Transuranic Waste: An Updated Systems Evaluation and Applications Assessment, PNL-4800, DOE Contract No. DE-AC06-76RLO1830, March 1987.

11. Environmental Protection Agency, "Toxicity Characteristic Leaching Procedure (TCLP). 40 CFR 268, Appendix I, U.S. Federal Register, Washington, D.C., 1988, pp. 724-738.

12. U.S. Federal Register, 55, No. 61, March 29, 1990, pp. 11,798-11,877.

13. M. J. Plodinec, C. M. Jantzen, and G. G. Wicks, "Stability of Radioactive Waste Glasses Assessed from Hydration Thermodynamics," Scientific Basis for Nuclear Waste Management, 7, edited by G. L. McVay, North-Holland, New York, 1984, pp. 755-762.

14. M. J. Plodinec, C. M. Jantzen, and G. G. Wicks, "Thermodynarnic Approach to Prediction of the Stability of Proposed Radwaste Glasses," Nuclear Waste Management Advances in 
Ceramics, 8, G. G. Wicks and W. A. Ross (eds.), The American Ceramic Society, Columbus, Ohio, 1984, pp. 491-495.

15. C. M. Jantzen and M. J. Plodinec, "Thermodynamic Model of Natural, Medicval, and Nuclear Waste Glass Durability," Journal of Non-Crystalline Solids, 67, 1984, pp. 207-233.

16. C. M. Jantzen,"Prediction of Nuclear Waste Glass Durability from Natural Analogs," Nuclear Waste Ma, agement II-Advances in Ceramics, 20, D. E. Clark, W. B. White, and A. J. Machiels (eds.), Arıerican Ceramic Society, Columbus, Ohio, 1987, pp. 703-712.

17. Materials Characterization Center, "MCC-1P Static Leach Test Method," Nuclear Waste Materials Handbook-Test Methnds, DOE/TIC-11400, Rev. 7, Technical Information Center, Springfield, Virginia, 1986.

18. Materiais Characterization Center, "MCC-3S Agitated Powder Leach Test Method," Nuclear Waste Materials Handbook-Test Methods, DOE/TIC-11400, Rev. 7, Technical Information Center, Springfield, Virginia, 1986.

19. C. M. Jantzen and N. E. Bibler, Product Consistency Test (PCT) for DWPF Glass: Part I, Test Development and Protocol, DPST-87-575, Savannah River Laboratory, Aiken, South Carolina, 1987.

20. S. O. Bates, In Situ Vitrification Product Evaluation Strategy, EGG-WTD-9148, EG\&G Idaho, Inc., Idaho Falls, Idaho, 1990.

21. J. G. Carter, S. O. Bates, and G. D. Maupin, In Situ Vitrification of Oak Ridge National Laboratory Soil and Limestone, PNL-6174, Pacific Northwest Laboratory, Richland, Washington, 1987.

22. B. C. Bunker, G. W. Arnold, E. K. Beauchamp, and D. E. Day, "iMechanisms for Alkali Leaching in Mixed Na-K Silicate Glasses," Journal of Non-Crystalline Solids, 58, 1983, pp. 295-322.

23. N. Kawanishi, H. Igarashi, H. Nagaki, and N. Tsunoda, Leaching Test on Chemical Durability of Glasses Containing Simulated High-Level Wastes, N831-80-01, Power Reactor and Nuclear Fucls Corporation, Japan, 1980.

24. EG\&G Idaho, Inc., Remedial Investigation/Feasibility Study Work Plan of the Subsurface Disposal Area, Radioactive Waste Management Complex, at the INEL, EGG-WM-8776, December 1989.

25. D. S. Goldman and D. W. Brite, "Redox Characterization of Simulated Nuclear Waste Glass," Joumal of American Ceramic Society, 69 (5), 1986, pp. 411-413. 


\subsection{Subsurface Contaminant Migration during Processing Is within Acceptable Limits}

\subsubsection{Description}

2.2.1.1 Description of the /ssue. For TRU-PTs, subsurface contaminant migration is thought to be controlled by three different mechanisms:

- Enhanced contaminant migration, due to the presence of subsurface structures

- Enhanced contaminant migration, due to the effect of gas volume surges from depressurizing buried waste packages

- Thermal gradients caused by the advancing ISV melt front.

2.2.1.1.1 Subsurface Structures-The issue of enhanced contaminant migration due to subsurface structures in the TRU-PTs specifically refers to the potential migration enhancement that may result from a more permeable soil/waste matrix that may occur in a buried waste environment. The presence of various waste forms in the TRU-PTs may inhibit the ability to completely surround the packages with soil, which may result in a large amount of void space surrounding the buried wastes. The presence of these void spaces may enhance the migration of certain volatile contaminants present in the melt, due to the potential evaporation and diffusion of these contaminants into the void spaces. The potential presence of large numbers of void spaces in the soil is more pronounced for random dump sites than stacked dump sites.

2.2.1.1.2 Depressurizing Buried Waste Packages-The issue of enhanced contaminant migration due to gas volume surges from depressurizing waste packages specifically refers to the potential migration enhancement that may result from the sudden release of gases from sealed waste packages in the TRU-PTs that suddenly yield or burst from the effects of the high-temperature ISV environment. Prior to depressurization, various volatile and semivolatile materials in the waste package may reach temper: "Ires high enough to evaporate. However, the vaporizing material will be forced to remain in the sealed waste package, which causes the package to pressurize. As the temperature of the waste package increases, the internal pressure increases, until it exceeds the yield strength of the sealed waste package. The waste package then depressurizes, and the vapors previously generated in these packages are either released to the ISV melt itself or to the soils surrounding the ISV melt front. The force of this depressurization may enhance the potential migration of contaminants from the melt via three mechanisms:

- The force of the pressurized release itself may be enough to send hazardous contaminants within the gases farther from the ISV melt front than would typically result from contaminant migration due to thermal gradients. Evidence of this phenomenon was seen for mercury in the fifth engineering-scale ISV test on INEL soils, which was recently conducted at Pacific Northwest Laboratory (PNL). ${ }^{1}$

- The resultant force of the gas release may result in the entrainment of additional contaminants present in the soils or ISV melt surrounding the depressurizing container.

- The rapid gas release may disturb the ISV melt or surrounding soils in a manner that channels for enhanced migration may be set up. This could result in enhanced contaminant migration, even after the depressurizing event occurs.

2.2.1.1.3 Thermal Gradients-If the TRU-PTs were to contain large quantities of volatile contaminants, the heat from the melt process could cause some of those contaminants to migrate from the melt product to unprocessed portions of the soil. Excessive subsurface contaminant 
migration could cause those portions of the unprocessed soil to be considered hazardous waste, as defined by 40 CFR 261.3, RCRA. $^{2}$ Unprocessed soil contaminated by the melt process could require further remediation. This would increase the cost of ISV at the INEL and, if further remediation were not viable, could result in ISV technology not meeting acceptance criteria for long-term product quality.

Transport of contaminants from the molten ISV melt front is a highly complex phenomenon, involving a potentially large number of mechanisms. The most obvious mechanism involves the vaporization and movement of volatile and semivolatile materials from the molten melt front, until a soil zone is reached in which the temperature is sufficient to cause the vapors to condense. This phenomenon, known as vapor retreat, ${ }^{3}$ is of varying influence for each specific contaminant (depending on its vapor pressure). However, other mechanisms have been postulated (e.g., molecular diffusion, carrier gas transport, capillary forces, soil column flow resistance, and liquid-vapor soil sorption) that either inhibit contaminant migration from the melt or, in some cases, favor contaminant migration into the melt. ${ }^{4,5,6}$ Further ISV modeling and testing is necessary to determine which of these mechanisms are dominant in relation to contaminant migration potential and to determine the effect of that dominance.

The major difference between a soil only application and the TRU-PTs, with regard to subsurface contaminant migration via thermal gradients, is that the TRU-PTs have waste packages that may or may not be more thermally conductive than the soil by itself. The presence of these waste packages may alter the spacing and shape of the soil isotherms surrounding the ISV melt. The magnitude of this variation within the TRU-PTs still needs to be determined.

2.2.1.2 Importance. The potential enhancement of contaminant migration due to subsurface structures is important if the enhanced migration pathway (i.e. void spaces, or soil/waste interfaces) extends beyond the area to be processed by the ISV melt. Therefore, it is important to identify where buried waste exists in the TRU-PTs to ensure that this waste will be processed by the ISV melt.

The potential for enhanced contaminant migration due to effects of gas volume surges from depressurizing containers is important due to the potential for sealed waste containers in the TRU. PTs. Previous studies have shown that the integrity of buried waste packages is seriously compromised after a number of years. In the early retrieval study, it was found that more than $65 \%$ of the buried 55-gal drurns were severely breached after 19-21 years underground. ${ }^{7}$ Although it might be possible that there are no sealed containers remaining in the TRU-PTs, it is assumed that they still exist to some degree.

In addition, the potential for enhanced migration due to waste package depressurizations is important, if the force of the depressurization is strong enough to cause the hazardous contaminants to migrate farther than they would under normal conditions (i.e. thermal gradients) or if the force of the depressurization changes the soil/melt structure enough to enhance the potential pathways for migration. Therefore, the importance of this issue depends on the potential magnitude of all typical waste package depressurizations that occur during ISV processing of the TRU-PTs.

Subsurface contaminant migration, due to thermal gradients, should only occur at the TRU-PTs if volatile and semivolatile constituents are present in large uncontained quantities (either outside a waste package or inside a package with a minimum amount of containment). Types of potentially hazardous migrating constituents assumed to be buried in the TRU-PTs include halogenated and aromatic organic compounds, semivolatile organic compounds, certain TCLP metals, radionuclides, and PCBs.

2.2.1.3 Influencing Factors. Factors that may influence subsurface contaminant migration include: 
- Location and amount of void spaces within the TRU-PTs (relative to specific surrounding soil isotherms)

- Properties of the TRU-PT soil (moisture content, permeability, thermal diffusivity, clay content, and porosity)

- Type of waste packages buried in the TRU-PTs (including potentially depressurizing waste packages)

- Type and concentration of contaminants present in the TRU-PTs (including the differential vapor pressures of various contaminants)

- Amount of melt above a sedled container

- Size and shape of the soil isotherms produced by the melt

- $\quad$ Certain ISV process variables, such as melt rate and power level.

\subsubsection{Closure Requirements and Roadmap}

\subsubsection{Assumptions.}

- Possible contaminants include volatile organic compounds (trichloroethylene, tetrachloroethylene, trichloroethane, and carbon tetrachloride), semivolatile organic compounds, TCLP metals (mercury, lead), semivolatile radionuclides (cesium, strontium), and PCBs.

- Contaminant migration will not be enhanced by subsurface structures, unless the structures are large enough to extend outside the area to be vitrified.

- Based on results from the early drum retrieval studies, it appears that the primary sealed waste packages that may be present in the TRU-PTs are 55-gal drums. ${ }^{8}$ However, it is possible that other sealed containers, such as metal tanks, gas cans, compressed gas bottles, and concrete vaults may also behave as sealed containers under ISV processing conditions. It can be safely assumed that all wastes stored in cardboard and large waste boxes will not be contained by the cardboard and wooden boxes themselves.

- Melt size does not contribute to contaminant migration, and therefore the effect of buried wastes on soil isotherm size and shape can be evaluated via a geometrically scaled-down ISV laburatory test.

- The relative concentration of uncontained gas generating materials in the TRU-PTs should not be enough to contribute signiticant carrier gas effects.

2.2.2.2 Requirements and Steps to Close issue. Note that the steps unique to subsurface structures, gas volume surges from depressurizing buried waste packages, and thermal gradient contributions to subsurface contaminant migration are separately identified.

1. Characterize the TRU-PTs via historical data and nonintrusive sampling to determine the following:

- Type, condition, size, and location of waste packages present in the TRU-PTs

- Location and size of any void areas present 
- Soil physical properties needed for models

- Type, concentration, and location of contaminants in relation to the waste packages present in the TRU-PTs.

2. Evaluate existing data from previous tests relative to contaminant migration. Determine whether the data is of sufficient quality to answer (wholly or partly) the question of contaminant migration. Possible sources for this information include:

- Geosafe tests on PCB-contaminated soils, for Northwest Transformer. ${ }^{5}$

- PNL tests on cesium-contaminated soils, for ORNL. ${ }^{4}$

- Penberthy Test. ${ }^{3}$

3. Characterization data application and lab testing for:

a. Subsurface Structures

- Use the TRU-PT site characterization data to define specific volatile and semivolatile contaminants that may migrate from the moving ISV melt front. Use the data to determine those surrounding soil isotherms where contaminants of concern may condense. Use analytical models and engineering calculations to estimate the location of these isotherms (relative to the ISV melt front), both during and after ISV processing.

- Apply the data on soil isotherm locations with characterization data on the type, size, and location of waste structures and void volumes in the TRU-PTs to determine if sufficient engineering controls (e.g., melt width) can be used so that none of the subsurface structures are large enough to extend outside the area to be vitrificd. If this is possible, then the issue of contaminant migration enhancement due to subsurface structures can be ignored.

- Perform laboratory-scale ISV tests or specially designed experiments to evaluate the effect of subsurface structures on contaminant migration enhancement. Use these tests to determine the enhanced permeability of the soil, if any, that results from the presence of buried waste packages. It may be necessary to use larger-scale ISV tests or computer models to verify these data.

b. Depressurizing Waste Packages

- Develop a scenario for a design basis waste package pressurization. Determine the maximum pressure that may develop, the volume of vapor potentially stored in the can, and the fastest possible rate of release from the depressurizing package.

- Using calculations, computer simulations, or ISV lab tests, determine the effect of this design basis waste pressurization on the potential for enhanced contaminant migration to the surrounding soils and into the basalt during ISV processing. Is the force of the pressurization enough to move hazardous matcrials farther from the melt than would be experienced due to thermal gradients of the ISV melt? How does the force of the pressurization affect the nonvolatile contaminants present in the ISV melt? Are the contaminants entrained with the depressurizing vapor? Is the force of the design basis pressurization enough to disrupt the melt such that a pathway is created for enhanced contaminant migration? 
If it can be shown that depressurizing waste packages do not enhance contaminant migration, then the issue is trivial and does not need further study. However, if contaminant migration is enhanced by canister depressurizations, the enhancement needs to be quantified before it is known whether the issue is a problem.

If the issue is a problem, a determination should be done as to whether there are innovations available to minimize this as a problem. Possible innovations include accelerated in situ corrosion of sealed metal containers, slowdowns, and thermal soaks of the buried waste pit during ISV processing, plus the use of vents beneath the ISV melt to channel the depressurizing gas into the ISV offgas system.

\section{c. Thermal Gradients}

- Evaluate the potential controlling mechanisms or influencing factors that may contribute to contamingant migration. Through modeling techniques and calculations, document the effects of thermal gradients on contaminant migration. Verify that melt size and rate, and carrier gas effects will not contribute significantly to contaminant migration. Verify how different buried waste configurations affect the size and shape of soil isotherms surrounding the melt.

- Perform laboratory-scale tests and/or specially designed experiments to evaluate the migration of volatile and semivolatile contaminants in contaminated soil and buried waste site applications.

- Use data from computer modeling, testing, and experimentation, and existing data to predict the size and shape of surrounding soil isotherms (how they are affected by various buried waste configurations) and the amount of migration that could be expected during ISV operations in the SDA TRU-PTs. To close the issue, it will be necessary to determine (a) peak concentrations of contaminants within the surrounding soil, (b) the percent of contaminant migration from the ISV melt during processing, and (c) the effect of thermal migration during cooling. The first item is necessary to determine if the concentration of contaminated material in the surrounding soil (following an ISV melt) is such that it could be considered a hazardous waste, as defined by RCRA. The second determination is necessary to evaluate the effectiveness of the ISV process for soils contaminated with volatile and sernivolatile contaminants.

Included in this step is a determination of the level of confidence for the migration prediction. If test scale is shown to not affect migration, and the effects of different constituents on contaminant migration are negligible, then the results from existing data and ISV laboratory tests and experiments can be used to evaluate the potential for contaminant migration during ISV processing of the TRU-PT.

4. Quantify potential contaminant migration. Determine how the enhanced migration of each contaminant, if any, compares to the requirements that have or will be set by the EPA for remediation activities. This comparison is the final step necessary for closure. If possible, use engineering controls (such as ISV remediation of the surrounding uncontaminated soil) to eliminate the potential migration enhancement. It may be necessary to perform leach tests that can be used to provide data in support of a risk assessment of the post-test soil surrounding an ISV melt.

\subsubsection{Related Technical Issues}

3.2 Hood and offgas treatment system seals maintain integrity. 
3.3 Hood and offgas system handle pressure transients.

\subsubsection{References}

1. T. M. Bergsman, J. W. Shade, and R. K. Farnsworth, "Fifth In Situ Vitrification Test of Simulated INEL Buried Waste Sites," Letter Report, Pacific Northwest Laboratory, Richland, Washington, 1991.

2. Code of Federal Regulations, 40 CFR 261.3, "Definition of Hazardous Waste," EPA Resource Conservation and Recovery Act, Revised 54 FR 36641, September 1, 1989.

3. H. L. Penberthy, "Failure of In Situ Vitrification Test on Mercury, Arsenic, Dieldrin, Aldrin," (Critique of Geosafe Article in Pollution Engineering, June 1990, p. 76-81), Pyro, August 1990, 32-F.

4. C. L. Timmerman and M. E. Peterson, "Pilot-Scale Testing of In Situ Vitrification of Arnold Development Center Site 10 Contaminated Soils, Appendix A: ISV Organic Destruction Mechanisms," ORNL/Sub/89-14384/2 (PNL-7211), prepared by Pacific Northwest Laboratory for HAZWRAP Support Contractor Office, Oak Ridge, Tennessee, February 1990.

5. S. C. Liikala, "Engineering-Scale Tests of In Situ Vitrification to PCB and Radioactive Contaminated Soils," presented at the Environmental Remediation '91 Conference, "Cleaning Up the Environment for the 21st Century," September 8-11, 1991, in Pasco, W'ashington. Pacific Testing Laboratories, Seattle, Washington, 1991.

6. J. Dragun, "Geochemistry and Soil Chemistry Reactions Occurring During In Situ Vitrification," Journal of Hazardous Materials, 26, 1991, pp. 343-364, Elsevier Science Publishers B. V., Amstcrdam.

7. J. R. Bishoff and R. J. Hudson, Early Waste Retrieval Final Report, TREE-1321, EG\&G Idaho, Inc., Idaho Falls, Idaho, 1979.

8. K. B. McKinley and J. K. McKinnely, Early Waste Retrieval Interim Report, TREE-1265, EG\&G Idaho, Inc., May 1978. 


\subsection{Any Residual Waste is Acceptable}

\subsubsection{Description}

2.3.1.1 Description of the Issue. This technical issue is a high priority for the TRU-PTs, because the waste forms in the pits and trenches are not homogenous. ${ }^{\text {The dissimilarities introduce }}$ obstructions that may inhibit complete encapsulation or dissolution of the waste in the melt, thus producing residual waste.

There are several adverse effects that could result from unacceptable amounts of unprocessed waste. Unprocessed waste may release radioactive/hazardous constituents into the underlying soil or basalt fractures. In time, these constituents may migrate into the groundwater. Unprocessed waste could also have the potential of emitting volatile organic and radioactive compounds into the air, degrading air quality and endangering the health of workers located within the pit area. If the remaining unprocessed waste was not remediated and failed to meet the applicable or relevant and appropriate requirements (ARARs) for site remediation, such as RCRA, EPA, and DOE requirements, ISV would be considered unsuitable as a viable remedial technology for the pit. Therefore, the potential impact to the environment from this residual waste must be assessed. The two technical areas of interest for investigation of this issue are:

- The melt shape is predictable and suitable for capturing waste intended to be captured

- The quantity of any waste that may not be encapsulated within the glass is acceptable.

2.3.1.1.1 Melt Shape-If the waste is not captured by the melt, the threat of hazardous contaminant releases will continue. To determine if the melt shape is suitable for capturing the waste, the following three influencing factors need to be investigated:

- Melt Width and Depth

An understanding of how the melt depth and width can be controlled during processing (and contributing factors of the waste form and soil) is essential to estimate how effective the melt is in capturing the intended wastes.

- Melt Channeling

Melt channeling can occur when part of the pit contents melt, or liquify, bcfore a surrounding object melts. When this occurs, the melted sections will tend to channel downward around the unmelted object and create preferential flow patterns. These flow patterns will be reinforced as the ISV process continues, increasing the probability of not dissolving all of the waste into the melt.

- Uncaptured Waste Between Adjacent Vitrified Blocks

When the amount of waste to be vitrified extends beyond the capabilities of a single ISV melt, vitrifying the waste in contiguous melts becomes an option. Concerns exist that these operations may result in unprocessed waste remaining in the soil between the adjacent vitrificd blocks.

2.3.1.1.2 Waste Encapsulated within the Glass-As the melt front progresses, the melt comes in contact with waste that starts to dissolve into the glass. The glass may surround some individual pockets of waste, which dissolve slower than the melt front progresses, resulting in a pocket of reacting waste within the melt. If power to the ISV process is cut before the surrounded waste can dissolve into the glass, a pocket of unprocessed waste may be present within the waste form. If the amount of this encapsulated, unprocessed waste is sufficiently large, the risk may be unacceptable, particularly for ISV retrieval operations (if required). 


\subsubsection{Importance.}

2.3.1.2.1 Melt Shape-As presently envisioned, the ISV process will involve many individual melts. As the remediation progresses, the melts will be "tied" together through melting an adjacent site next to a previous melt. In this manner, all wastes will be captured by the ISV process. However, without knowing the location (vertical and horizontal position) of waste to be captured or without having the ability to control the geometry of the melt, one cannot ensure that the intended waste was captured. To minimize the quantity of waste left unprocessed in the soil, a thorough understanding of process knowledge and control of the melt geometry in terms of shape, width, and depth are required. These phenomena were observed during the 1990 IFT tests. ${ }^{2}$

The TRU-PT depth is $4.4-6.5 \mathrm{~m}$ from the ground elevation to the top of the basalt layer beneath the pit. This depth includes overburden, waste, and underburden. It is assumed that a significant portion of the contaminants of concern in the pits/trenches have migrated below the waste area to the soil above the basalt. This is a reasonable assumption, since it is known that several pits and trenches were flooded several times. Therefore, it is desirable that ISV captures all waste and soil underburden down to the basalt. It is not known to what extent contaminants may have migrated into the basalt layer.

The ISV process creates molten soil that will preferentially flow through the path of least resistance. Some waste may be encapsulated by the melt but not dissolved into the meit. This quantity of residual waste must be evaluated for its potential environmental impact. In addition, loss of melt (e.g., into a large void space) impacts ability to continue ISV operations.

In overlapping of ISV melts for site remediation, there is the potential for some of the radioactive or hazardous waste to not be incorporated into the final contiguous ISV product. This situation would result in possible hazardous contaminant release to the environment.

2.3.1.2.2 Waste Encapsulated within the Glass-The potential impact of encapsulated waste should be minimal for two reasons. First, the amount of this waste should be only a minor fraction of the total. If the power is maintained to the melt for a sufficient time after the last of the waste to be processed by a given setting of the ISV has been contacted, little of this waste would be generated. Second, this encapsulated waste would be protected by an outer covering of very durable glass to restrict a migration path and carrier. At worst, the unprocessed waste would be no worse than the original waste.

\subsubsection{Influencing Factors.}

2.3.1.3.1 Mett Width and Depth-Two major factors must be considered when addressing the issue: first, the characteristics of the area to be treated by the ISV process, and second, how melt operations can be conducted to control melt depth and width.

Previous ISV field tests have shown that the waste being vitrified can play an important factor in the resulting depth and width of the melt. Soil-only ISV field tests have produced glass monoliths of a rounded nature. In FY 1990, two intermediate field tests conducted at the INEL indicated that the vitrification of buried wastes, when processed with electrode feed operation, may result in a relatively deep but narrow vitrified zone-not as rounded as the previously observed sc.l tests at PNL. In a recent large-scale test at Hanford, the melt did not reach the target depth before the width of the melt approached the width of the hood, requiring shutdown of the electrodes to terminate the meit. It is believed that a layer of stones in the crib inhibited downward growth and enhanced width growth to the point the intended wastes could not be captured by the melt. This Hanford Crib test did not employ moveable electrodes, the use of which is now part of the standard ISV operations and provides additional control of melt growth. 
2. Perform a computer simulation of the flow pattern based on the melting temperatures and locations of the pit contents.

3. From the computer simulation, approximate the amount of residual waste left unprocessed in the pit. Approximate the percentage of error associated with this simulation.

4. Compare the residual waste amount with the acceptable amount, factoring in the error percentage.

5. If the quantity of residual waste approximated with the computer simulation, including the possible error percentage, is acceptable, the issue is closed.

6. If the quantity of residual waste is unacceptable, is a method available to reduce the quantity of residual waste (such as longer ISV processing or adding soil to increase melt volume)? If so, repeat steps $2-4$ including this method. If not, this issue cannot be closed.

\subsection{Uncaptured Waste Between Adjacent Vitrified Blocks-}

1. Characterize the pit.

2. Determine the number of melts required.

3. Use lab-scale tests to determine the effects of employing the ISV process next to a vitrified block. Determine the effects of overlaps.

4. Use current ISV techniques with the site characteristics to cstimate the size of the melts needed to adequately contain the waste to be processed.

5. Through use of computer modeling, determine the distance or degree of overlap needed belween ISV melts to ensure efficient ISV melt processes. If overlap is required, determine the necessary cooling time for adjacent melts.

6. Use engineering calculations to estimate the amount of unprocessed waste that will remain between vitrified blocks. Will the amount of remaining waste be accessible and can it be retrieved or contained if it is contaminated beyond acceptable limits?

7. Use risk assessment calculations to estimate the threat that the remaining waste poses to human health. Will the remaining waste meet the ARARs for site remediation?

This issue will meet closure requirements if the remaining waste between vitrified blocks can he retrieved or contained. passes the appropriate regulations, and does not pose a threat to human health or the environment.

2.3.2.2.4 Unprocessed Waste within the Glass is Acceptable-.The general outline for closure is presented in Figure 4.

\subsubsection{Related Technical lesues}

2.1 The durability/quality of the product is acceptable. 
2.3.1.3.4 Unprocessed Waste within the Glass is Acceptable-The primary factors influencing the possibility of encapsulated waste within the glass are (a) the solubility of the waste in the molten glass, (b) the surface area of the waste, (c) the rate at which the melt progresses outward, and (d) the position of the waste within the melt.

If the solubility of the waste is low, the waste may not dissolve into the melt. Chromium is an example. The melt would encapsulate that portion of the waste. However, if a waste is insoluble in the melt at $1,400^{\circ} \mathrm{C}$ or higher, it would be insoluble in water and would not likely represent a significant threat to the environment.

If a waste is a large monolith and has a low surface area (such as a large sphere of metal), the time required to melt/dissolve the waste would be slow and the processing time would need to be sufficiently long to react with the waste.

If the rate at which the melt front progresses outward is fast, the melt may progress by the waste. If the melt reaches the prescribed limits and the power is turned off, the encapsulated waste may not have time to react with the melt before the melt cools. This may also occur if the waste is near the outer edges of the melt and the power is turned off.

\subsubsection{Closure Requirements and Roadmap}

2.3.2.1 Assumptions. None.

\subsubsection{Requirements and Steps to Close Issue.}

2.3.2.2.1 Melt Width and Depth-In order to define what is required for closure of this technical issue, the following questions must be answered:

- Where are the wastes you intend to treat? Data required to support this includes a review and evaluation of historical waste disposal records, geophysical method detection of subsurface structures, sampling, and analysis.

- Where are the melt boundaries after processing? Data supporting this evaluation includes final depth (electrode insertion measurements), interpretation of mclt geometry (based on comparison with past melts in similar conditions), and geophysical method detection of melt geometry.

- Where are the melt boundaries during processing? Electrode insertion depth, prediction based on past experience, real-time geophysical measurements.

- How will the melt progress vertically and horizontally through a given waste composition and siructure based on selected operating conditions? Past experience (lab test operations versus field test operations, analytical modeling of melt face movement through various material, and operating conditions.

- If the melt is not capturing the intended wastes, what processing parameters can be varied to ensure capture? Laboratory testing and field testing experience to optimize process conditions-power input, overburden depth, electrode feed rate, electrode design, electrode configuration/spacing.

\subsection{2.¿ 2 Met Channeling-}

1. Idently iilc appropriate location of large metal objects and/or voids within the pit. 
Other characteristics of the soil/wastes that impact the depth and width of the melt include the amount of buried waste relative to surrounding soil that will be captured by the melt, the melting temperature of the soil, metal layer (such as packed metal drums), and the rate the melt progresses (a function of many factors, including the amount of water in the soil, thermal conductivity, soil constituents, etc.).

Melt operations can be modified to control melt depth and width. Operating factors include electrode feed rate, electrode spacing, power input, electrode configuration (i.e., number and position), electrode design (e.g., "hot-tip" electrodes).

2.3.1.3.2 Mett Channelling-The contents of the pit and their location within the pit influence melt channeling. ${ }^{2}$ The melting temperatures of some of the atypical metal objects in the pit, such as a stainless-steel vault and a $100,000 \mathrm{~kg}$ carbon steel reactor, will melt at different temperatures than other constituents such as wood scrap, filters, and rags. The location of metal drums and atypical metal objects with respect to other faster melting objects such as the wooden or cardboard boxes will influence the flow pattern.

\subsection{Uncaptured Waste Between Adjacent Vitrified Blocks-}

a. Type and Quantity of Buried Waste. A major factor in determining whether the quantity of uncaptured waste remaining between adjacent vitrified blocks will be acceptable is the type and quantity of buried waste that exists in the pit before ISV operations begin. If the pit is highly contaminated with radioactive/hazardous waste, then remediation might require more than one melt. The overlap of these melts may miss some of the adjacent waste material, increasing the possibility of unacceptable levels of uncaptured residual waste remaining between blocks.

b. Contiguous Melts. The following questions arise if conditions at the pit require more than one ISV melt to adequately contain the buried waste:

- How many melts will be required and are feasible to contain the waste at the pit?

- How close can ISV be operated next to a vitrified block?

- How much melt overlap is necessary to contain all of the waste in the pit?

- How much cooling time is required before ISV can be operated next to a cooling vitrified block? Contiguous melting tests at PNL have shown that contiguous melting should not be attempted unless sufficient time has been allowed for the adjacent vitrified block to cool. Otherwise, the cooling ISV melt may pull some of the joule heat away from the adjacent ISV melt, limiting melt growth.

c. Size, Depth, and Width of the Melt Product (melt geometry). Governing the size, depth, and width of the melt product is more important to adequately capture the waste to be processed.

d. Soil Characteristics. Soil moisture, composition, stratigraphy, density, disturbance (for example, from previous drilling activities), soil/waste ratio, depth to waste material, depth to basalt, groundwater location, hydraulic conductivity (thermal and electrical), viscosity, and specific heat ali affect the ISV process. Soil characteristics can greatly influence melt geometry, retrieval options, and the feasibility of ISV at the pit. 


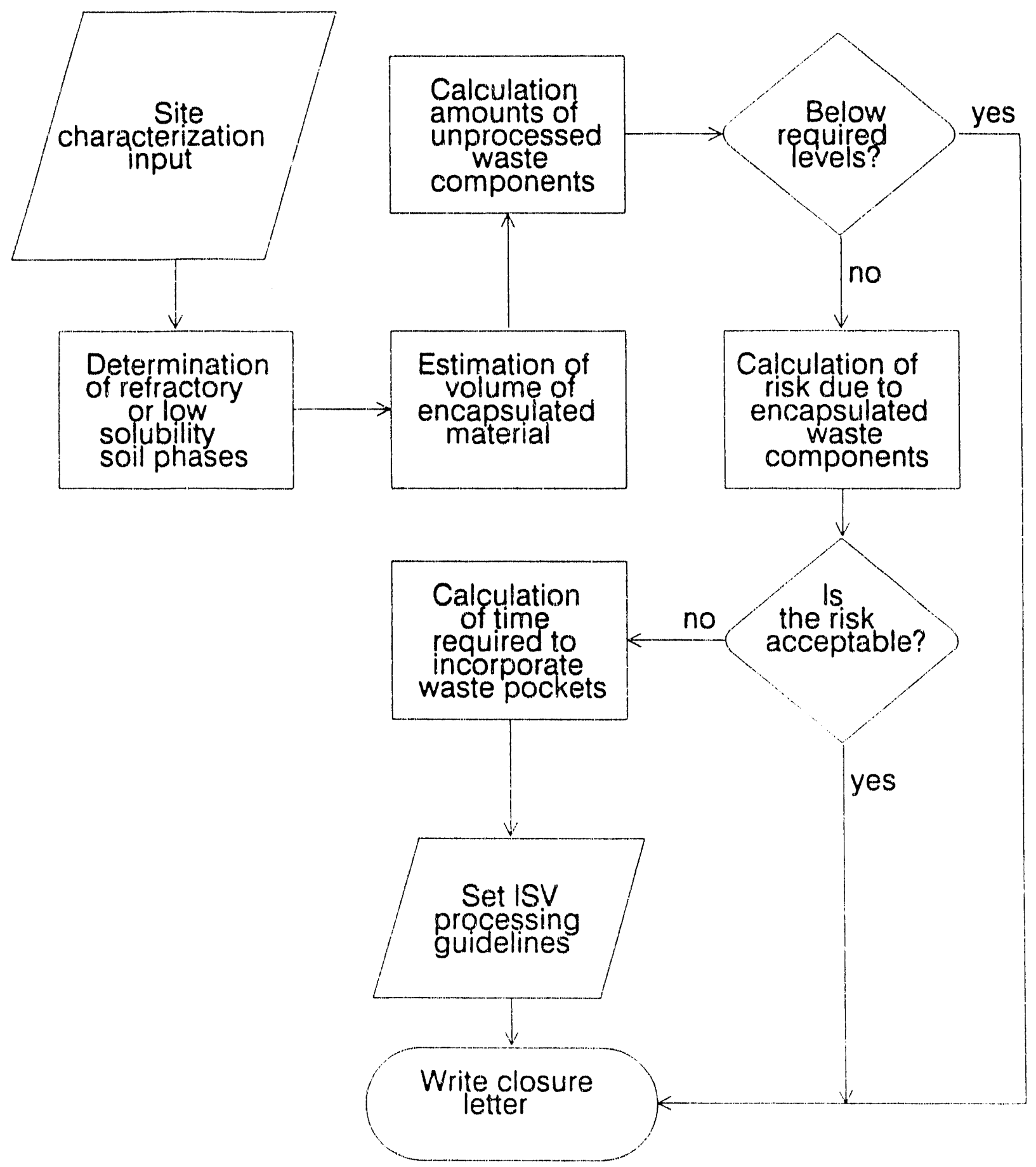

Figure 4. Roadmap for closure of the technical issue "The quantity of any waste that may be encapsulated (unprocessed) within the glass is acceptable." 


\subsubsection{References}

1. K. J. Liekhus, Nonradionuclide Inventory in Pit 9 at the RWMC. EGG-WM-10079, Rev. 0, January 1992.

2. R. A. Callow, et al., IFT Final Report, August 1991.

\subsubsection{Bibliography}

1. S. C. Liikala, Engineering.Scale Tests of In Situ Vitrification to PCB and Radioactive Contaminated Soils, Pacific Testing Laboratories, September 1991.

2. W. F. Bonner et al., Unpublished Research Results "Increasing ISV Depth: A Task Force Report," PNL, December 1990.

3. J. L. Buelt, V. F. FitzPatrick, C. L. Timmerman, J. G. Carter, and K. H. Oma, In Situ Vitrification of Transuranic Waste: An Updated Systems Evaluation and Applications Assessment, PNL-4800, DOE Contract No. DE-AC06-76RL01830, March 1987.

4. Arenholz \& Knight, A Brief Analysis and Description of TRU Wastes in the SDA of the RWMC ai the INEL, February 1991. 


\subsection{Secondary Waste Streams (Effluents from the Offgas Treatment System, Scrub Solutions, HEPA Filters, Decontamination Solutions, etc.) Are within Acceptable Limits.}

\subsubsection{Description}

2.4.1.1 Description of the Issue. The ISV process generates secondary waste as part of normal operation of the offgas processing system. This waste includes stack offgases, used scrub solutions, used HEPA filters, and solutions resulting from cleanup and flushing of scrub tanks. It is essential that the secondary wastes can be minimized and disposed of in conformance with applicable regulations. In the case of offgases, they must not exceed established limits. For purposes of a single test, it is essential to verify that secondary wastes can be stored and disposed of without violating any regulations. Ultimately, data required relative to secondary waste are the amounts generated and the costs to treat and dispose of these wastes. Such costs are a factor in the overall feasibility of the ISV process.

2.4.1.2 Importance. It is necessary to maintain secondary wastes within acceptable limits to have a viable remediation technology. Failure to do so would preclude ISV as a suitable technology.

2.4.1.3 Influencing Factors. Two factors influencing the production of secondary waste streams are the amount and types of primary waste, and the hood temperature. Another factor is the amount of volatile and semivolatile organic compounds present in the waste. Volatile and scmivolatile organic compounds could entrain radioactive compounds during processing, producing mixed (hazardous and radioactive) secondary waste. Effluents from the offgas treatment system will have to meet the regulations governing treatment, storage, or disposal of secondary waste. The type of offgas system would also affect the amount of secondary waste. For example, a dry system would have different secondary waste volumes.

\subsubsection{Closure Requirements and Roadmap}

2.4.2.1 Assumptions. None.

\subsubsection{Requirements and Steps to Close Issue.}

1. Characterize the site to determine the types and concentrations of buried waste.

2. Identify all the potential secondary waste streans using site characterization data. Use existing data to chart amounts of secondary waste deposited in the scrub solutions, HEPA filters, and decontamination solutions, and amounts of effluents emitted by the stack offgases from previous tests. Use these data to estimate (by modeling and calculations) the amounts that could be produced during ISV operations at the TRU.PTs.

3. Identify the appropriate or relevant and applicable requirements (ARARs) and any other regulatory limits for offgas emissions.

4. Document whether the system will meet the ARARs and other limits for offgas emissions. Record secondary waste data (amounts generated, levels of hazardous constituents, levels of radioactivity) from future field tests.

5. Identify requirements for storage and disposal of the secondary waste (i.e., RCRA). Prepare cost estimates for disposal of wastes generated. 
- Identify what techniques are available for disposal of secondary wastes, including recycling into the next ISV melt.

- Prepare cost estimate for secondary waste disposal per volume of waste remediated.

- Calculate volumes of secondary treated waste per volume of primary waste remediated.

6. Document that a waste management process is in place for the storage and treatment of secondary wastes, including mixed (hazardous and radioactive) waste. This waste management plan must conform to company mandates, DOE orders, and ARARs.

\subsubsection{Related Technical lssues}

2.1 The durability/quality of the product is acceptable.

3.2 Hood and offgas treatment system seals maintain integrity.

3.4 Risks due to exposed waste are within acceptable limits. 


\section{SAFETY ISSUES}

\subsection{Possibility of Criticality Is Avoided}

\subsubsection{Description}

3.1.1.1 Description of the /ssue. The issue of criticality refers to buried waste materials that are transuranic in nature. Because of their ability to emit neutrons as part of their decay cycle, these TRU materials are capable of sustaining a nuclear chain reaction, provided there is enough material present, the material is sufficiently concentrated, and the moderation properties of the surrounding waste materials are suitable. The potential exists for a critical condition to develop in the TRU.PTs, if these conditions are present.

As a result of past and ongoing nuclear activities throughout the DOE complex, a large amount of TRU-contaminated waste materials have been generated and disposed of at sites throughout the DOE complex. To make sure that a critical condition does not result from the disposal of these materials, various disposal procedures and TRU-contamination levels have been set. In general, a major purpose of these waste disposal procedures and limits is to place the TRU materials in a waste environment that limits the potential for a criticality to occur in the contaminated soil or buried waste site. Once in place, it can be generally assumed that the TRU materials will continue to reside in a noncritical condition.

However, during most remediation activities, the concentration of TRU materials, as well as the modcrating environment surrounding these materials, will drastically change. This is particularly true of buried waste sites, such as the TRU-PTs, due to the extremely heterogeneous nature of disposal. A concern exists that the change in TRU concentration and moderator environment may be sufficient to cause a critical condition to develop during ISV processing.

Previous studies have shown that it is improbable for a critical condition to develop during ISV processing of contaminated soil sites. ${ }^{1,2}$ The reasons for this conclusion are:

- The ISV waste form is relatively homogeneous in concentration, causing any critical materials to be uniformly distributed through the melt, acting as a dilution effect.

- The ISV process results in an effective decrease in the moderating environment surrounding the critical material, due to the loss of water and organic materials in the buried waste sitc.

- The amount of transuranic materials entrained to the offgas during ISV processing of contaminated soil sites is generally not high enough to cause a critical condition to develop in the ISV offgas system.

- The transuranic materials are sufficiently oxidizing to preclude the reduction and eventual concentration of these materials in a metal layer at the bottom of the melt.

However, for ISV processing of buried waste sites, such as the TRU-PTs, a number of additional concerns associated with criticality exist.

- Some of these transuranic materials may have been buried in their reduced form, and could remain in a metallic form that would settle and concentrate at the bottom of the ISV melt, if the kinetics were slow enough.

- Many of the transuranic materials are disposed of in either an inorganic or organic sludge that would pyrolyze or evaporate in front of the advancing ISV melt front. The 
transuranic materials may then be able to settle into a critical condition prior to being incorporated and dispersed in the ISV melt.

- The presence of sealed containers filled with vapor-generating materials in the TRU-PTs will allow for surges in offgas releases to the ISV offgas system. These offgas surges result in a significant increase in the amount of particulate entrainment released to the ISV offgas system. ${ }^{3}$ As a result, there is an increased potential of a critical condition developing in the ISV offgas system during ISV processing of the TRU-PTs.

3.1.1.2 Importance. The potential development of a critical condition is the primary technical issue associated with ISV processing of the TRU-PTs. The development of a critical condition could expose the ISV operating staff to a significant, possibly fatal dose of radiation, depending on where the criticality occurs (in the melt, on top of the melt, or in the ISV offgas system). In addition, the development of criticality may also result in the release of significant amounts of energy, accompanied with ionization of water, that could generate significant pressures beneath the melt. This would then result in a melt explosion that would breach the ISV offgas containment and release significant amounts of contaminated material to the environment. For these reasons, the issue of melt criticality needs to be fully resolved prior to implementing ISV processing on a TRU-PT site.

3.1.1.3 Influencing Factors. The potential development of a critical condition during ISV processing of a TRU-PT depends on a number of factors, all related to the condition of the buried waste site:

- Chemical condition of the transuranic materials in the buried waste site (oxidized, metallic, etc.).

- Size and shape of the transuranic materials, if in their metallic state.

- The types of transuranic waste packages in the site, the amount and spatial distribution of transuranic contamination within the various waste packages, and the type of materials (oxidizing/reducing, moderating, etc.) surrounding these contaminants within the waste package.

- The amount of potentially pressurizing containers within the TRU-PT site and their location relative to transuranic contamination within the site.

\subsubsection{Closure Requirements and Roadmap}

\subsubsection{Assumptions.}

- It is assumed that ${ }^{239} \mathrm{Pu}$ accounts for the greatest fraction of fissionable radionuclides present within a TRU-PT. In addition, ${ }^{239} \mathrm{Pu}$ has one of the smaller subcritical mass limits of all transuranic radionuclides. Therefore, the analysis of criticality potential within a TRU-PT needs to only evaluate the critical potential for ${ }^{239} \mathrm{Pu}$. The assumption that ${ }^{239} \mathrm{Pu}$ is the primary transuranic contaminant within a TRU-PT needs 10 be confirmed by characterization data, however.

- It is assumed that the transuranic material in the TRU-PT was disposed of in a manner such that a critical or near-critical condition does not exist prior to ISV processing of the waste site.

- It can probably be assumed that most of the transuranic material present in a TRU-PT was either in an oxidized form at the time of disposal, or has become completely oxidized over the past 20 years of burial. However, a number of hypothetical situations exist that may be present in the TRU-PT, where the potential for oxidation was limited (e.g., metallic 
plutonium shavings in lathe oil). For this reason, the assumption of complete oxidation will not be used.

- It can be assumed, because of the silicate-based nature of soils, that there is no potential that a sufficiently reducing environment will exist during ISV processing of the TRU-PTs to cause the reduction of any transuranic oxides.

- It should be assumed that the proposed limits for transuranic contamination levels in the TRU waste packages were not always followed and that the waste packages may contain 100-200\% more transuranic material than was allowed. This assumption is based upon the recollections of various operations personnel involved in TRU disposal activities in the $1950 \mathrm{~s}$ and $1960 \mathrm{~s} .^{4}$

- It should be assumed that a large number of sealed containers, such as 55-gal drums, have lost their integrity over the past 22 years underground. This assumption is based on the results of an Early Waste Retrieval (EWR) study, which found that 65\% of the retrieved drums were severely breached after less than 20 years of storage. ${ }^{5}$ However, the issue of drum pressurization and transuranic entrainment in the ISV offgas system still necds to be evaluated, because of the potential for some pressurized containers to remain in the ISV offgas system.

\subsubsection{Requirements and Steps to Close Issue.}

1. Characterize the TRU-PT to determine the presence and location of transuranic material, the condition of the transuranic materials (oxides, metals), and the types of materials (including waste packaging) immediately surrounding the transuranic contaminations. Identify maximum bounding concentration (amount) limits and use in calculations.

2. Identify all of the potential mechanisms by which transuranic and moderating material may be moved around or transformed during ISV processing. Identify which of these mechanisms could result in a critical condition.

3. Use information on the concentration of transuranic material in the TRU-PT to estimate the final concentration of transuranics in the solidified ISV waste form and determine if this is sufficient to produce a critical condition.

4. Use experimental tracer studies to evaluate the potential transport of transuranics during ISV operations.

5. Use site characterization data to estimate the potential for a critical condition to occur in any of the buried waste packages prior to coming in contact with the downward moving ISV melt front.

6. Evaluate any other perceived mechanisms that could produce a criticality.

\subsubsection{Related Technical Issues}

2.1 The durability/quality of the product is acceptable.

\subsubsection{References}

1. J. L. Buelt et al., In Situ Vitrification of Transuranic Waste: An Updated Systems Evaluation and Application Assessment, PNL-4800 Suppl. 1., Pacific Northwest Laboratory, Richland, Washington, 1987. 
2. R. A. Libby and A. L. Doherty, ISV Criticality Safety Analysis of INEL Soil, INEL-90-002, Pacific Northwest Laboratory, Richland, Washington, 1990.

3. R. A. Callow et al., In Situ Vitrification Application to Buried Waste: Final Report of Intermediate Field Tests at the Idaho National Engineering Laboratory, EGG-WTD-9807, EG\&G Idaho, Inc., Idaho Falls, Idaho, 1991.

4. T. E. Wierman, ISV Field Test Siting and Source Term, EDF Serial Number BWP-ISV-024, March 20, 1990.

5. J. R. Bishoff and R. J. Hudson, Early Waste Retrieval Final Report, TREE-1321, EG\&G Idaho, Inc., Idaho Falls, Idaho, 1979.

\subsubsection{Bibliography}

1. N. Levtiz et al., "Volume Reduction and Salvage Considerations for Plutonium-Contaminated Ferrous Metals," AlChE Symposium Series, Vol. 72, No. 154, 1976, pp. 86-89.

2. M. G. Seitz, T. J. Gerding, and M. J. Steindler, Decontamination of Metals Containing Plutonium and Americium" DOE Report ANL-78-13, June 1979.

3. G. L. Copeland, R. L. Heestand, and R. S. Mateer, Volume Reduction of Low-Level Contaminated Metal Waste by Melting-Selection of Method and Conceptual Plan, DOE Report ORNL/TM-6388, June 1978.

4. B. Heshmatpour and G. L. Copeland, The Effects of Slag Composition and Process Variables on Decontamination of Metallic Wastes by Melt Refining, DOE Report ORNL/TM-7501, January 1981.

5. B. Heshmatpour, G. L. Copeland, and R. L. Heestand, Decontamination of Transuranic Waste Metal by Melt Refining, ORNL/TM7951, Oak Ridge National Laboratory, Oak Ridge, Tennessee, 1981, p. 25.

6. C. W. Hobbick, D. R. Schatz, and G. D. Aden, Distribution and Removal of Radionuclides in Molten Stainless Steel, DOE Report RHO-CD-1444, 1981. 


\subsection{Hood and Offgas Treatment System Seals Maintain Integrity}

\subsubsection{Description}

3.2.1.1 Description of the issue. The hood and offgas treatment system designs must prevent the release of hazardous and/or radioactive waste. The hood's purpose is to contain the gaseous effluents from the ISV process, to provide a confined area for combustion, and to direct the effluents to the offgas system. The offgas treatment system scrubs, filters, and cools the hazardous vapors and entrained solid waste from the hood. To prevent the release of hazardous materials, the confinement hood and offgas treatment system must withstand corrosion, fires, and maintain seal integrity. The hood must also be designed to contain any vapor release from the melt or surrounding soil. This section discusses the technical issues associated with seal integrity, corrosion, and fires.

3.2.1.1.1 Confinement Hood and Offgas Treatment System Seals-The hood has seals to the ground, to the offgas line, and to the electrodes. These seals must withstand the transient pressures and temperatures expected within the hood. Under normal conditions, in which there is no pressure buildup in the hood, the hood interior is at a negative pressure with respect to the external environment, and seal leakage is into the hood. However, if a positive pressure occurs in the hood, radioactive and/or hazardous leakage may occur through the seals into the environment, unless properly designed. A possible hazard also exists if matter ejected from the melt has enough force to breach the seal between the hood and the ground.

In the event of a complete failure of all offgas systems, a slight over-pressure of the hood will occur. The hood could incorporate a HEPA filter to provide offgas decontamination in the event of pressurization and backflow. ${ }^{1}$ Backflow can occur through the surrounding soil around the base of the hood when the hood has positive pressure. In this situation, the HEPA filter would be bypassed. The hood needs to be designed to prevent this from occurring.

The offgas treatment system has containment seals in numerous locations including the hood to offgas line and the offgas line to the offgas trailer. ${ }^{2}$ The containment seals need to contain any possible airflow out of the piping into the surrounding environment. This outgoing airflow could occur during any situation which causes over-pressures in the hood or offgas treatment system. Since the TRU-PTs contain many possible combustibles and explosives, these abnormal operations are more likely to occur. ${ }^{3}$ This assumption is based on the contents of Pit 9 , which is considered representative of the other TRU-PTs.

The offgas hood and the lines entering the offgas trailer will be hot during operation and part of the cooldown phase. The seals must be able to withstand the high temperatures. Fluid pressures during operation of the test are not expected to be excessive. Therefore, potential problems from this source are minimal. ${ }^{1}$

In all soils a certain amount of void space exists due to porosity of the soil. The porosity of the soil is the ratio of void volume to total volume of the soil. As the soil melts during the ISV process, the porosity decreases because the molten soil flows together releasing the void spaces. This increases the density of the soil; and since the mass of the soil remains the same, the volume of the soil decrcases. This causes the melt to subside below the soil surface. As the melt subsides, part of the unmelted soil forming the boundary (sidewall) to the melt can collapse into the melt, impacting the seal between the hood and the soil. If the hood is improperly designed, the resultant gap could allow particulates and offgases to escape into the surrounding environment. The offgases evolved from the TRU-PTs could contain sulfur and chlorine containing compounds, nitrates, products from pyrolysis of organic compounds, and radioactive waste. These materials must be removed in a controlled manner by the offgas treatment system to protect the environment and operation personnel. To avoid loss of hood/soil seal integrity, design of the hood needs to take into account the sluff angle of the TRU-PTs soil, assuming no molten sidewall is created. 
3.2.1.1.2 Fires-Fires can affect the containment capabilities of the hood in two forms. First hood fires could breach the hood and thus release hazardous or radioactive waste to the environment. Second, underground fires could promote the release of hazardous or radioactive vapors outside the hood, if the fires propagate outside the confines of the hood.

Fires have occurred during ISV testing that have breached the integrity of the hood. ${ }^{4}$ These fircs have all occurred with fabric hoods containing combustible coatings. The hood design should ensure (a) that combustion in the hood plenum does not result in temperatures high enough to cause failure of hood material or electrode seals, and (b) that melt splatter does not cause failure of hood material or electrode seals.

Ignition and propagation of underground fires is complex and a function of many variables such as waste composition, moisture content, available oxidizers, and ambient pressure. A combustible material can spontaneously ignite if enough oxidizing agents and high enough temperatures are present. The insulating properties of the surrounding matter determine whether the heat produced is retained and the chemical oxidation rate continues to increase. If the insulating properties are such that the oxidation rate increases, the temperature will likewise increase until the combustible material cventually reaches its ignition temperature.

3.2.1.1.3 Mett Ejection-During the ISV process, gases in the melt may eject melt material onto the hood. Melt materials may erode the hood through corrosion, abrasion, or from extreme heat. Waste containing a significant amount of combustible materials could result in excessive gas generation and melt splattering. Combustible wasie in sealed containers (e.g., metal drums) can result in rapid venting of pyrolyzed gases and particulates. For example, a pilot-scale test, PSFT-3, conducted by PNL evaluated ISV perfo mance with a 55-gal metal drum containing simulated combustible waste and soil buried between electrodes. ${ }^{2}$ When molten soil contacted the drum, rapid venting of pyrolyzed gases and carbonaceous particulates occurred for about 30 minutes.

Recent events during a full-scale operational acceptance test (OAT-2) at Geosafe and a fullscale underground test at PNL have given increased importance to understanding mechanisms for water and/or other volatile material transport underneath the melt. ${ }^{4,5}$ Large amounts of water and power loss are two common characteristics of these tests. During normal ISV operations, pressure is relieved from a melt via off gassing in the form of bubbles passing through the melt. It is postulated that another pressure venting phenomenon is the release of pressure through a sintered friable layer of soil imrnediately adjacent to the melt around its outer perimeter surface. When power is secured to a melt, it immediately starts cooling. The melt will cool faster at its outer surface, where heat sinks in the form of the unmelted soil and the atmosphere exist. The melt surface will form a cold cap or at least become more viscous than the center of the melt. (This depends on the length of time the power is secured). The sintered soil will cool and the glass will essentially form a seal with the unmelted soil around the melt perimeter. When the power is restored, the cold cap and perimeter seal prevent normal off gassing. Vapor-generating materials (like water) will not be able to escape causing pressures to build up beneath the melt and eventually eject part of the melt. Large melt bubbles and associated expulsion (of varying magnitude) may be a possibility during vitrification of the soil. The mechanisms of vapor transport must be studied (analytically and experimentally) in greater detail to ensure that excessive melt splatter will not occur during ISV processes at the TRU. PTs.

3.2.1.1.4 Thermally Altered Zones-Thermally altered zones are sections of the soil surrounding the melt through which gaseous contaminants may migrate due to thermal gradients within the soil. These zones are bounded by the melt/soil interface and the isotherm at which condensation occurs for the specific contaminant of interest.

3.2.1.1.5 Corrosion-The following is a description of corrosion mechanisms written for Type 304 austenitic stainless steel, components in the hood and offgas treatment system. 
a. Attack by Sulfur and Its Compounds. Nickel-containing alloys are attacked by sulfur and it compounds $\left(\mathrm{H}_{2} \mathrm{~S} \text { and } \mathrm{SO}_{2}\right)^{6,7}$ through a process called sulfidation. ${ }^{a}$ Nickel and sulfur form NiS, an eutectic compound that melts at $303{ }^{\circ} \mathrm{C} \quad\left(579^{\circ} \mathrm{F}\right){ }^{8}$ Therefore, nickel-containing alloys are not considered "usefully resistant" to sulfur-containing atmospheres above $315^{\circ} \mathrm{C}\left(599^{\circ} \mathrm{F}\right) .^{9}$ This is especially true under reducing conditions ${ }^{10}$ because the protective chromium oxide layer has less of a chance to reform after being disrupted. The concentration of sulfur in the gaseous environment that can cause sulfidation is as low as $1 \% .^{\circ}$

Some sources of sulfur in the TRU-PTs are metal sulfates like ferric sulfate and magnesium sulfate. ${ }^{3}$

b. Attack by Chlorine and Its Compounds. Chromium-containing alloys such as $304 \mathrm{~L}$ stainless steel are attacked by chlorine and its compounds (principally $\mathrm{HCl}$ ) in both high-temperature gases and aqueous solutions. High-temperature chlorine attack proceeds by forming metal halide scales, which give some protection to the metal. However, these metal halides have a very high vapor pressure so that they will vaporize after reaching a certain temperature, leaving the base metal unprotected (see Reference 7). This probably results in general attack (similar to the corrosion of iron when exposed to air). Corrosion is also a problem at lower temperatures when aqueous $\mathrm{HCl}$ is beginning to precipitate from the gas. This results in chloride stress corrosion cracking ${ }^{\mathrm{c}}$ or pitting (see Reference e). Aqueous chloride attack occurs when $\mathrm{HCl}$ iocally disrupts the $\mathrm{Cr} 2 \mathrm{O} 3$ protective layer. This results in pitting and, eventually, perforation. Chloride stress corrosion cracking can also occur.

Within the TRU-PT's, the sources of chlorine are chlorides and chlorinated organics like carbon tetrachloride, trichloroethane, and trichloroethylene (sce Reference 3).

c. Altack by Carbon. Chromium-containing alloys are attacked by carbon at high temperatures. The carbon combines with the chromium, forming chromium carbides. This causes the alloy's chromium content to decrease, leaving it susceptible to other types of attack (see Reference 7).

Ano her type of attack occurs when oxidizing and reducing conditions alternate. The high-carbon areas of the alloy formed when reducing conditions dominated will be burned out and the metal oxidized. This will lead to perforation (see Reference 7).

Sources of carbon in the TRU-PTs are primarily organics and the graphite electrodes (see Reference 3).

\subsubsection{Importance.}

3.2.1.2.1 Confinement Hood and Offgas Treatment System Seals-Since the TRU-PTs could contain many possible mechanisms for explosion, combustion, and other means of over-pressurizations, hood containment and offgas treatment system seal leakage could pose a threat to personnel and the environment. ${ }^{3}$ During the tests that have resulted in hood fires, loss of offgas

a. Type 304 stainless steel nominally contains $18 \%$ chromium and $8 \%$ nickel.

b. Personal communication with R. E. Minzia, Westinghouse Idaho Nuclear Company, Inc. (WINCO), Jdaho Falls, Idaho, April 2, 1991.

c. Personal communication with R. E. Minzia, Westinghouse Idaho Nuclear Company, Inc. (WINCO), Idaho Falls, Idaho, April 3, 1991. 
containment occurred. ${ }^{4}$ The released offgas has been nonhazardous, but during ISV of TRU-PTs, this would not be the case. Therefore, it is important that the hood integrity is never lost.

3.2.1.2.2 Fires-An underground fire related to the ISV processing of a waste site is not a problem unless it causes one or more of the following to occur:

- Surface settlement (ground subsidence) resulting from subsurface decomposition that may affect normal ISV operations by affecting hood containment. This poses a risk to workers and may expose previously buried waste.

- Venting of noxious vapors from the surface of the soil that may pose a risk to workers or the cornmunity.

3.2.1.2.3 Melt Ejection-Melt ejection is a major concern at the TRU.PTs. Many buried containers exist within the pits that could promote large pressurizations if sealed.

3.2.1.2.4 Thermaly Altered Zones--The thermally altered zones of interest are those areas (i.c., isotherms) where there is a potential for hazardous material emissions to the atmosphere. The movement and location of these isotherms need to be evaluated to determine the ISV hood dimensions needed tu contain the hazardous emissions released from both the melt and the surrounding soils during ISV processing.

3.2.1.2.5 Corrosion--Corrosion of the hood by the offgases is one of the safety issues that needs to be resolved before the treatability study of the TRU-PTs can be completed. If sufficient corrosion of the hood occurs, it could result in breaching of the hood during ISV operations and the escape of effluent gases. These gases will probably contain acids, sulfur containing compounds, chlorine containing compound, mercury, nitrates, pyrolysis products of organic compounds, and radioactive waste. Treating this gaseous effluent is akin to treating the gaseous effluent from an incinerator. Another effect of these corrosive gases is degradation of the offgas treatment system. Most of the offgas treatment system is made of austenitic stainless steel, and wet hydrochloric acid vapors and aqueous hydrochloric acid will pit austenitic stainless steel. In addition, the acid gases in combination with moisture could degrade the HEPA filters. Degrading the offgas treatment system will probably reduce its efficiency and occur slowly over time. It is not known whether this reduced efficiency will result in untreated offgas release to the atmosphere.

3.2.1.3 Influencing Factors. The contents of the TRU-PTs to be vitrified determine the requirements placed upon the hood containment and offgas treatment system seals. Since the probability of pressure transients is high based on the contents of Pit 9 [reference 3], design measures in the hood, ofifgas treatment system, and the seals should be taken to reduce the harmful effects of pressure transients due to explosions or combustion. Void volume, melt aspect ratio, melt rate, potential sluff angle, and hood design need to be considered when considering sidewall collapse.

Fackors influencing the formation of underground fires are (a) location, size, and type of combustible or pyrophoric materials, (b) location, size, and type of oxidizers, (c) properties of the soil, and (d) surrounding temperature.

3.2.1.3.1 Location, Size, and Type of Combustible or Pyrophoric Materials-If a continuous layer of combustible or pyrophoric materials, in combination with an oxidizer, extends beyond the confinement hood, underground fires may propagate outside the confines of the hood and release hazardous materials to the environment, endangering workers at the ISV site. Some items like wood, paper board, or oil rags may be present in extensive layers or zones so that combustion could propagate outside the containment zone. Ponding of combustible liquids could produce similar combustion propagation. The ignition temperature for combustion depends on the type of material.

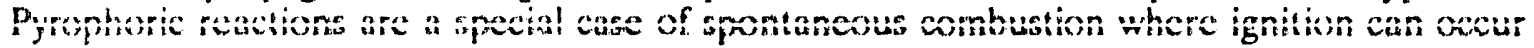


immediately on exposure to oxidizers. Ignition temperatures for pyrophoric materials are low compared to ignition temperatures for combustible materials. Pyrophoric materials can include metals with high surface areas (powders and lathe shavings), organics such as oil or grease rags, partly decayed vegetation, and certain hydrides. Combustible or pyrophoric materials within the TRU-PTs are bottles of organic liquid (toluene and benzene); organic sludge composed of degreasing agents, lathe coolant, hydraulic oils, carbon tetrachloride, trichloroethylene, tetrachloroethylene, and oils; oils containing polychlorinated biphenyls; alcohols; organic acids; paper; and wond. Most of these materials were placed in drums, but corrosion of the drums has probably allowed most of the material to escape to the soil. ${ }^{3}$

3.2.1.3.2 Location, Size, and Type of Oxidizers-To create and maintain an underground fire, oxidizers must be present. The source must also continuously extend beyond the confinement hood to propagate underground fires beyond the hood. Oxidizers found in the TRU-PTs are nitrates and sulfates (see Reference 3). The results of recent lab scales tests on pyrolysis during ISV have shown that metal carbonates in the soil may thermally decompose producing a carbon dioxide atmosphere within the soil nearest the melt front. The carbon dioxide, can supply oxygen to organics in the soil. ${ }^{11}$

3.2.1.3.3 Properties of the Soll-Certain combustible materials in the presence of adequate oxygen will oxidize. The insulating properties of the surrounding soil determine whether the heat produced is retained and the chemical oxidation rate increases. If the insulating properties are such that the oxidation rate increase, the surrounding temperature will likewise increase until the combustible material eventually reaches its ignition temperature.

3.2.1.3.4 The Surrounding Temperature-As previousiy mentioned, combustion and pyrophoric processes depend on the temperature. If the surrounding temperature rises to the ignition temperature, combustion or pyrophoric reactions will occur.

Hood materials and pressure-generating compounds within the soil influence potential hoxd fires. The contents of the TRU-PTs to be vitrified will determine the extent of the possible ejected matter and combustible material. Ejected glass should be expected based upon the previous test observations, and the expected contents of the TRU.P'Ts. 3,5 Barriers to gas transport through the soil, such as walls, soil and rock layers, and basalt influence the issue of melt ejection.

Factors that can influence melt ejection are: soil permeability, soil porosity, moisture content, gas generating compounds within the soil, melt front rate, power into the electrodes, soil specific heat, and soil thermal conductivity.

Factors that can influence the movement of soil isotherms (and contaminants) away from the melt during and after ISV processing are thermal conductivity and the thermal diffusivity of the contaminated areas in the TRU.PTs. The presence of soil saturated with water, acids, and salts may enhance the potential for isothermal movement away from the melt, both during and after ISV processing. Another factor that may influence this issue is the relative homogeneity of the TRU-PTs, hoth in terms of soil, contaminant, and storage container distribution and composition. In addition, certain (though not all) ISV large-scale melts have had melt aspect ratios (ratio of melt width to melt depth) that were higher than expected. This may also affect the required dimensions of the ISV hood.

\subsubsection{Closure Requirements and Rosdmap}

\subsubsection{Assumptions.}

- It is assumed that the contents of the pit to be vitrified can be known well enough to iuentify ine causes for possibie pressure increases, and io predici maximum iemperaiures and pressures within the hood. 
- Existing data are extensive enough so that correlations can be made among factors that contribute to sidewall collapse. In particular, the existing data can be used to determine the sluff angle range of the TRU-PT's site soil.

- The contaminants of interest will migrate to a temperature range in the soil that is directly related to the vapor pressure-temperature relationships of the contaminant itself. If this is true, it should be possible to calculate the potential contaminant release to the environment at various distances (and peak soil temperatures) away from the melt. The assumption could be verified via air monitoring of the soil surface at various predetermined locations during ISV processing.

\subsubsection{Requirements and Steps to Close Issue.}

\subsection{Confinement Hood and Offgas Treatment System Seals-}

1. Characterize the contents of the pit to be vitrified. Identify explosive and combustive contents within the TRU-PTs to be vitrified and any explosive or combustive reactions that could occur within the hood and offgas treatment system. Identify the constituents that may produce excessive pressures and cause the release of hazardous/radioactive material into the environment. Also, identify the items that may cause matter to be ejected from the melt. Review the data that will be used to determine the sluff angle of the SDA soil, the potential subsidence of the soil, and the potential aspect ratio (width/depth) of the melt. Information such as porosity, grain size, density, and total void volume will be useful. Bounding maximum limits should be determined.

2. Using the expected pressurizations calculated for the hood design and for the offgas treatment system, identify the hood and offgas treatment system containment seal requirements. To ensure continuity in expected contents, compare the identified explosive. and combustive contents identified in step 1 with those used to perform the expected pressurizations analysis.

3. Calculate the maximum pressure that could occur based upon the results of step 2 . Calculate the possible load on the hood due to matter ejected from the melt, as found in step 2. Calculate the maximum expected temperature within the hond based upon step 1.

4. Determine if hood and offgas treatment system seals exist, or can be designed, for adequate containment based upon the results of step 3 .

5. Use modeling techniques and calculations to predict potential width and amount of sidewall collapse. An upper limit to the void volume can be calculated based on the porosity of the soil, the number of containers in the soil to be vitrified, and the method by which the containers are stacked. The VULCAN ${ }^{d}$ computer code can be used to predict the size of the melt and the amount of subsidence that may orcur. The sluff angle can then be found from the literature based on the type of soil. If the hood is large enough to contain the melt and the sluffed soil, the issue is resolved. During an ISV test, a video camera could be used to monitor sidewall collapse.

6. This issue is closed when hood seals can be designed, or exist, to contain the pressures, forces due to ejected material, and temperatures calculated in step 3. If the hood is not adequately designed, redesign the hood or reduce the horizontal spread of the melt to accommodate the potential sluffing of the soil.

4. VULCAN, developed by the INEL, Version 4.4, May 8, 1991. 


\subsection{Fires-}

1. Characterize the site through sampling and analysis. Analysis of historical records could present some of the contents within the buried waste sites, although inaccuracies and temporal degradation may make it necessary to sample the waste sites before applying the ISV process. Perform scoping calculations on underground fires using historical information. If the scoping calculations indicate a potential problem, perform site characterization through sampling. The sampling and analysis should identify combustible and pyrophoric materials and oxidizers within the site area. It should also include the thermal conductivity and specific heat of the soil to determine the insulating properties of the soil. Data from the site characterization study should be used to approximate the potential amount of melt splatter and maximum temperatures from combustion of hood gases. Existing data from other hood fires and on hood materials should be reviewed.

2. Determine the mechanisms needed for underground fire generation and propagation. This may include details on the amount and form of oxidant required, ignition temperatures, surface area of pyrophoric materials, etc. This can be achieved analytically with experimental validation.

3. During the ISV process, install temperature measuring devices within the soil to determine if underground fires are occurring.

\subsection{Melt Ejection-}

1. Characterize the site by reviewing historical dumping records and core sampling and analysis. In particular gather information on soil porosity, permeability, and moisture content. Also gather information on gas producing materials within the soil (c.g. volatile organics, carbonates, nitrates, and sulfates).

2. Based on the above information perform a numerical analysis using the TOUGH ${ }^{\mathrm{e}}$ code to determine the pressure expected beneath the melt.

3. Perform experiments to examine single effects and integrated effects of vapor release for the purpose of developing and validating the TOUGH code.

4. If the analysis from the TOUGH code shows the pressure beneath the melt will not eject the melt, the issue is closed.

5. If TOUGH predicts pressures large enough to eject molten soil, either redesign the hood to handle the ejected molten soil, reduce the rate at which the melt progresses, or reject the use of ISV at this site.

\subsection{Thermally Altereo Zones-}

To close the issue of hood containment of the thermally altered soil zones, it will be necessary to:

- Determine how far the soil isotherms of interest extend away from a TRU-PTs melt during and after ISV processing.

e. TOUGH, developed by Lawrence Berkeley Laboratory, under the University of California system, June 1987. 
- Determine where the isotherms of interest come in contact with the surface of the soil.

- Determine the effects that clean soil overburden has on contaminant migration to the surface.

- Determine the time span required for the hood to remain over the melt and thermally altered zone to prevent the escape of hazardous vapors. The isotherms near the soil surface need to be low enough to prevent the release of hazardous vapors to the atmosphere.

- Determine if the existing ISV hood is large enough to contain any hazardous matcrial emissions released from either the melt or the thermally altered soil surface.

The steps towards closure of this issue are:

1. Characterize the site to obtain a good understanding of the thermal conductivity and specific heat of the soil in the area to be processed. These soil properties are very important in predicting the aspect ratio of the melt, as well as the distance the soil isotherms of interest my move away from the melt. The conductivity and specific heat will be affected by contaminant type and concentration, location and type of buried containers, and void volume.

2. Determine the factors that influence contaminant emissions from both the ISV melt and the soil surrounding the ISV melt. Are the contaminant emissions directly related to soil and melt surface temperatures? This determination may be done using either existing data, engineering calculations, computer modeling, or specially designed experimental testing.

3. If contaminant emissions are related to the temperatures of the melt and the surrounding soil, use computer modeling to determine the potential release of contaminants from the surrounding soil surfaces at various distances away from the melt. Computer codes like VULCAN, MAGMA ${ }^{f}$, and FIDAPg12,13,14 can be used to make the se calculations.

4. If the relationship of contaminants to the melt and soil temperatures cannot be established, use the dat a from step 2 to derive the relationship needed. If needed, perform an ISV test evaluating the release of contaminants from the surrounding soil surfaces at various radial distances from the melt.

5. Determine if the ISV hood is large enough to capture the hazardous emissions released from the surrounding soil during ISV. If the hood is large enough, this issue is resolved. If the hood size is not sufficient, evaluate the cost to design and fabricate a sufficiently sized hood. Some stray emissions can be expected and dealt with through the use of appropriate mechanisms and procedures (i.e., radiation and gas detection devices, personnel protection, etc.).

6. Determine the time span needed for the hood to remain over the melt and thermally altered zone after the ISV process is finished. Again computer codes like VULCAN, MAGMA, and FIDAP can calculate the time span.

1. MAGMA, Jeveloped by the INEL, Version 1.0, November, 1991.

g. F!DAP, developed by F!uid Dynamics Internationa! !nc., Yersion 6.! Apri! !oo!. 


\subsection{Corrosion-}

1. Determine the amount and species of all chemicals and other buried waste in the TRU-PTs. Of special interest are acids, organic compounds, bases, sulfur-containing compounds, and chlorine-containing compounds. For bounding calculations, use the highest concentrations of the above compounds. This information can be found from dumping records and site characterization data.

2. Use the above characterization data, existing data in the literature, and computer modeling to determine the following:

a. Offgas temperature and composition resriting om vitrification of the TRU.PTs waste. The chemical composition, temperature, and pressure of the offgas in the hood and the offgas treatment system can be predicted by the codes SOLGASMIX ${ }^{h}$ and VESTA ${ }^{i}$. SOLGASMIX predicts the chemical compounds most likely to result given temperature, pressure, and elemental composition. VESTA calculates the temperature, pressure, and flow fields within the hood after combustion.

b. Degradation of various hood and offgas treatment system materials after exposure to the offgases. This can performed by first reviewing the literature on corrosion and then applying that knowledge to the hood and offgas treatment system materials.

3. Check the corrosion levels of existing hoods and offgas treatment systems. If the existing hoods and offgas treatment systems can withstand the predicted corrosion from the site to be vitrified, the issue is closed.

4. If the current hoods and offgas treatment systems would fail given that predicted corrosion, design a new hood and offgas treatment system. This can be accomplished by using techniques to reduce corrosion. It may be possible to use current hoods and offgas treatment systems by applying corrosion resistive techniques.

5. Use the information about potential corrosion within the ISV components and design and implement a preventive maintenance program.

\subsubsection{Related Technical Issues}

2.2 Subsurface Contaminant Migration During Processing.

3.3 Hood and Offgas Treatment System Handle Pressure Transients.

\subsubsection{References}

1. D. A. Lamar, T. J. McLaughlin, Safety Analysis Documentation: Lange-Scale Radioactive Testing of the In Situ Vitrification Process at the 2.16-Z-12 Crib, Pacific Northwest Laboratory, May 1987.

2. J. L. Buelt, C. L. Timmerman, K. H. Oma, V. F. FitzPatrick, J. G. Carter, In Situ Vitrification of Transuranic Waste: An Updated Systems Evaluation and Applications Assessment, PNL.4800 Suppl. 1, March 1987.

h. SOLGASMIX, developed by Oak Ridge National Laboratory, October 24, 1987.

i. VESTA, developed by the INEL, Version 1.0, October 17, 1990. 
3. T. E. Wierman, ISV Field Test Siting and Source Term, EDF No. BWP-ISV-024, March 1990.

4. K. A. Roy, "Geosafe Suspends ISV Operations Following Fire at Test Site," Hazmat World, September 1991, p. 16.

5. "In Situ Vitrification Test Failures Forcing Reevaluation of Process," Report on Defense Plant Wastes, August 16, 1991, p. 143.

6. "Corrosion," Metals Handbook, 13, 9th ed., Metals Park, Ohio: Amcrican Socicty for Metals, 1987.

7. Corrosion Basics: An Introduction, Houston, Texas: National Association of Corrosion Engineers, 1984.

8. E. A. Brandes (ed.), Smithells Metals Reference Book, 6th ed., London, England: Butterworths, pp. 11-382.

9. H. H. Uhlig and R. W. Revie, Corrosion and Corrosion Prevention, 3rd ed., New York: Wiley, 1985.

10. P. D. Harvey (ed.), "Stainless Steel at High Temperatures," Lesson 15, Stainless Steels, Metals Park, Ohio: Metals Engineering Institute of the American Society for Metals, 1978.

11. R. E. McAtee and W. K. Reagen, "In Situ Vitrification Laboratory Pyrolysis Studies of the High-Temperature Chemistry of Organic Materials in RWMC Soils," Letter Report, EG\&G Idaho, Inc., Idaho Falls, Idaho, September 30, 1991.

12. P. E. Murray and M. O. Fryer, Simulation of Heat Conduction and Electric Fields During In Situ Vitrification of Soil: Method Design and Verification, EGG-WM-9045, EG\&G Idaho, Inc, Idaho Falls, Idaho, September 1990.

13. P. R. McHugh and J. D. Ramshaw, A Computational Model for Viscous Fluid Flow, Heat Transfer, and Melting in In Situ Vitrification Melt Pools, EGG-WTD-9845, EG\&G Idaho, Inc., Idaho Falls, Idaho, November 1991.

14. G. L. Hawkes, Influence of Natural Convection on Melt Shape During In Situ Vitrification, reprint from HTD-Vol. 172, Heat Transfer in Geophysical Media, Book No. G00635, 1991, American Society of Mechanical Engineers. 


\subsection{Hood and Offgas Treatment System Handle Pressure Transients}

\subsubsection{Description}

3.3.1.1 Description of the lssue. Pressure transients within the hood and offgas treatment system result from explosions within the hood or offgas treatment system, ruptures of pressurized containers within the soil, void volumes within the soil, combustion within the hood, and waste falling from the sidewall onto the melt. To describe the issue, a discussion of each source follows.

3.3.1.1.1 Explosions-An explosive is "any substance or device that will produce, upon release of its potential energy, a sudden outburst of gas, thereby exerting high pressures on its surroundings." ${ }^{1}$ Explosions during the ISV process may occur within, near, and above the melt. The pressure fluctuations from the explosions can affect the offgas treatment system.

An explosion within or near the melt can occur if the melt encounters explosive compounds (such as organic nitrates) or military ordnance, or if a shock wave from an explosion within the melt detonates neighboring ordnance or ignites other combustible materials. Explosions occurring close to the ground surface create pathways for vapors to escape beyond the hood boundaries. Many wastes with restricted air access, such as cellulose material and nitric acid, ignite spontaneously when exposed to oxidizers. ${ }^{2}$

Gases at explosive concentrations can react with air and detonate within the hood. For example, hydrogen gas formed within the reducing environment of the melt explodes upon reaching the oxidizing atmosphere within the hood.

Limited sources for explosions exist within the offgas treatment system. Pressure fluctuations from explosions within the hood could travel throughout the offgas treatment system. Explosions duc to combustion within the offgas treatment system will probably not occur, because most of the combustion transpires within the confinement hood.

3.3.1.1.2 Breach of Pressurized Sealed Containers-As the ISV melt approaches a sealed container, the temperature around the container increases, which (a) increases the pressure and temperature within the container and (b) weakens the strength of the container and the seal gaskets of the container. Eventually the container or seal breaches and releases high-pressure vapors.

Thermal expansion of the container contents, vapor generation, and chemical reactions (i.c., combustion, pyrolysis) increases the pressure within the container. Containers nearly full of liquids will most likcly rupture due to thermal expansion. Pyrolysis, volatilization, chemical reactions, and decomposition promote vapor generation. Certain materials within sealed containers (i.e., empty gas cans, nitrates, and carbon sources) promote explosions. ${ }^{3,4}$

The type and thickness of the container material influence the mechanism by which failure occurs. Containers rupture due to interaction with the melt (i.e., corrosion, melting, and stress failures). In most cases, the higher temperatures of the surroundings near the melt reduce the yield stress of the container allowing the container to breach at a lower pressure than at ambient conditions. Thin-walled ferrous containers will probably fail due to reduced yield stresses Thick-walled composite materials and glass containers may fail due to thermal stresses. Pyrolysis will probably cause the failure of plastic containers. ${ }^{3}$ Thermal decomposition of container seals may promote containment breaching.

Drums stored in pits for long periods may corrode. A number of factors influence containers corrosion. These factors include moisture, loss of protective paint, waste constituents, material quality, and age of drums. Corrosion breached $65 \%$ of the 55 -gal drums retrieved by the Early Waste Retrieval (EWR) project. The drums have sat within the EWR pits nearly 20 years. The drums 
within the TRU-PTs have been disposed for a longer amount of time (22-35 years). On the basis of similar dumping mechanisms, the TRU-PTs may have a similar percentage of breached drums as the EWR pits. Based on a conservative estimate within an Engineering Design File, 35\% of the buried drums within Pit 9 could contain liquids. ${ }^{2}$

At PNL in July 1991, an ISV large-scale test halted due to some molten glass escaping the hood. The ISV melt had a higher than expected rate of bubbling and gas release. It was the first large-scale test on an underground tank using a 6,000 gal vessel. At Geosafe in March 1991, splatter from the melt caused the combustible fabric hood to catch fire. A contributing factor may be the pressure transient caused by the simultaneous release of water-filled drums. ${ }^{5}$

3.3.1.1.3 Vold Volumes-Vapor and gases accumulate within void volumes. As the ISV melt fills the void, the vapors and gases escape to the surface. These vapors and gases may promote pressure transients within the hood and offgas treatment system and cause the melt to splatter. Void volumes include dissolution cavities, empty or partially filled containers, random cavities between large rigid objects dumped in piles, and slumped areas. Void volumes may be sources of underground oxygen for combustible materials promoting underground explosions or fires, locations for liquid pooling, and areas where the melt may disconnect from the electrodes. ${ }^{3}$

The area in TRU Pit 9 under consideration for ISV has 1,568 55-gal drums. On average, 968 of those drums are $70 \%$ filled. Approximately 600 drums are nearly empty. The total volume of the pit under consideration is 514 cubic meters. The total void volume is 185 meters. Therefore, under worst case conditions, $36 \%$ of the total volume comprises voids. ${ }^{2}$ If Pit 9 is characteristic of the other TRU-PTs, a large amount of void space is present. This, however, does not take into account concrete vaults, tanks, and other void volumes that may be present in the TRU.PTs.

3.3.1.1.4 Combustion-During the ISV process, most of the organic material pyrolyzes into volatile byproducts which rise to the surface of the melt and combust upon contact with the air above the melt. However, a limited amount of organic material may combust in and around the melt, if air is present. Combustion can occur within the soil if combustible material reacts with oxidizers within the soil. The pressures and temperatures due to combustion depend on the type and amount of byproducts formed by pyrolysis and the amount of air or oxidizers available for combustion. ${ }^{6,2}$

3.3.1.1.5 Waste Falling from Sidewall onto the Mell Surface-During the ISV process, the melt subsides below the initial soil surface forming a boundary or sidewall of unmelted soil around the melt. Part of this unmelted soil may collapse onto the melt. The potential for sidewall collapse increases when the soil subsidence increases. The release of vapor depends on the amount of volatile material within the collapsed sidewall. Void spaces created by the storage of 55-gal drums will increase the amount of subsidence within a hazardous waste site as opposed to a contaminated soil site without waste containers.

3.3.1.2 Importance. Large pressure transients will affect both the confinement hood and the offgas treatment system. Large pressure transients could compromise the vacuum pressure maintained within the hood, breach the hood and/or offgas treatment system, promote melt splatter onto the hood, and promote flow rates that exceed the capacity of the offgas treatment system. Over-pressurization could cause a blockage within the offgas system or allow some of the hazardous and/or radioactive offgas to pass through the scrubbers and HEPA filters untreated. If blockage occurs, a HEPA filter installed in the hood could vent the offgas. ${ }^{7}$ Gases from void volumes and sealed containers and generated from pyrolysis pass through the soil and create pathways for additional releases of gases.

If large pressure transients, over-pressurization or explosions could (a) generate high-speed fragments from the damaged confinement hood or offgas treatment system, (b) release hazardous and/or radioactive waste released into the atmosphere, or (c) promote fires from the release of chemicals or expelled burning fragments. Such damage will affect the equipment, ISV personnel, and 
environment. The offgases evolved from the TRU-PTs could contain hydrogen gas, sulfates, nitrates, sulfur dioxide, carbon monoxide, carbon dioxide, semivolatile inorganic vapors, entrained radioactive particulate, and organic gases. ${ }^{2}$ The hood design must contain pressure transients, withstand melt splatter, and maintain a vacuum pressure to ensure containment of hazardous and radioactive waste. The offgas treatment system design must contain pressure transients and adequately treat the hazardous and radioactive material in the offgas.

\subsubsection{Influencing Factors.}

3.3.1.3.1 Explosions-Factors that can influence the probability of explosions are (a) types of explosive substances within the pit or generated in the melt, (b) presence of voids within the pit, and (3) conditions in the pit during the ISV process that are conducive to explosions.

3.3.1.3.2 Breach of Pressurized Sealed Containers-The influencing factors are container waste type, waste volumes, container volumes, container depth, container thickness, container material, number and size of containers relative to other site materials, and the presence of oxidizers that could lead to combustion or pyrophoric processes.

3.3.1.3.3 Vold Volumes-Influencing factors are void volume size, location, and content.

3.3.1.3.4 Combustion-The following factors influence the combustion processes within the confinement hood which affect the offgas treatment system: ${ }^{4}$

- Composition, amount, concentration, and location of organic and combustible materials within the vitrification zone

- Composition, amount, concentration, and location of catalytic materials within the vitrification zone that may accelerate pyrolysis

- The amount of air within the containment hood and the amount and composition of oxidizers within the vitrification zone

- Temperature and composition of the melt

- The design of the hood

- Design of the offgas treatment system.

The composition of organic, combustible, and catalytic materials within the TRU-PT and the confinement hood will influence the offgas flow rate.

The composition of air within the containment hood and the amount of oxidizers within the vitrification zone will influence the offgas generation caused by combustion due to the fact that all combustion processes need a source of oxygen either in the form of a gas, or in another form such as a nitrate or chlorate. In a normal ISV process, air is drawn into the confinement hood and mixed with the pyrolyzed offgases released from the melt. The temperature within the hood is sufficient to promote combustion. To properly destroy the organics and combustibles within the vitrification zonc, oxygen must be supplied at a sufficient rate to ensure complete combustion. However, the combined air and offgas flow rates may not exceed the capacity of the offgas treatment system. The amount and rate of combustibles determines the amount and rate of oxygen needed to achieve complete combustion.

A higher temperature will increase the mass and volume of combustibic vapors leaving the melt. A gas cooler should remove a major portion of the heat load from the offgas before quenching. The combustion air and offgas flows should be separated by a heat shield that extends below the hood's 
ceiling. The heat shield will effectively direct combustion air toward the surface of the vitrification zone and keep the hood-skin temperatures lower. ${ }^{4}$

The design of the confinement hood must be capable of handling the transient pressure pulses caused by combustion, while maintaining the desired vacuum pressure within the hood. The hood must also be properly designed to prevent circulation dead spots where combustible gases may accumulate. Finally the hood must be designed such that transients due to combustion and other pressure pulse generating mechanisms may not cause structural fatigue to the hood.

The design of the offgas treatment system must have sufficient capacity to contain and treat gaseous releases that result from combustion and other sources such as void volumes and sealed containers. The offgas flow rate must be large enough to contain the maximum potential flow rate from vitrifying soil inclusions while providing sufficient air for combustion and maintaining the vacuum pressure within the hood. Gases from pyrolysis can carry with them to the offgas treatment system an amount of radionuclide elements associated with the combustible waste. The offgas system must anticipate and treat those wastes.

3.3.1.3.5 Waste Falling from Sidewall onto the Melt Surface-Contributing factors that may affect the possibility of an emission include soil contamination in the sidewall material, potential sidewall formation, melt size, melt rate, offgas evolution rate, soil conditions, void volume, overburden, hood design, arrangement of buried waste packages in the TRU-PTs, and offgas treatment system design.

\subsubsection{Closure Requirements and Roadmap}

\subsubsection{Assumptions.}

- The sites within the TRU-P'Ts can be characterized.

- The explosions possible within and above the melt will have a small enough brisance to allow operation of the ISV process with proper component design. In other words, the hood can be designed to handle the effects of possible explosions.

- Most of the containers are 55-gal ferrous drums. This assumption is based on the EDF file for TRU Pit $9 .^{9}$

- $35 \%$ of the drums in the TRU-PTs are able to contain liquid. See comments in description of the issue.

\subsubsection{Requirements and Steps to Close Issue.}

\subsection{Explosions-}

1. Characterize the site to be vitrified to determine the types of explosives possible in the TRU.PTs under consideration (e.g. low explosive, bursting pressure vessel, vapor cloud, explosive dust, etc.). The TRU-PTs present a conducive environment for explosions, since they may contain enclosed vessels, hydrogen, and various other chemicals. If intact ordnance is contained or potentially contained in the TRU-PTs, ISV should not be applied (page 145, reference 6). The TRU Pit 9 contains 55-gal drums containing wet inorganic sludges, organic sludges absorbed in calcium silicate, sludges consisting of liquids absorbed in cement, sludge evaporator salts, and near empty drums containing roughly 1 gal of oil each. The organics and water contained in these drums may promote large vapor relcases. ${ }^{2}$ 
2. Have an expert in explosive materials review the characterization clata to determine if potentially explosive material is contained within the soil to be vitrified.

3. Determine if explosion potential is possible under ISV conditions.

4. Determine the most probable source location(s) of the explosion(s).

5. Estimate the maximum energy release, release rate, and pressure using any method appropriate to that type of explosion. Some methods are given in reference 2, chapter 2, and reference 10 . Calculate the uncertainty of the estimates.

6. Predict the explosion effects using already established charts and tables (see reference 2, chapters 4 and 8 ).

7. Determine if the hood design meets the following criteria if explosions are possible within the hood:

a. Corners should be designed to reduce over pressures (caused by multiple reflections in corners).

b. Exterior architectural details should be avoided, which could be hazardous in the event of accidental over-pressure within the hood (such as falsework or signs on the hood).

c. Hood joint design should allow critical joints to develop the full strength of the hood base material.

d. Ductility of the hood material should be maintained at all operational temperatures. The material and construction should be able to absorb large amounts of energy in a ductile manner, without catastrophic failure in the structure as a whole.

e. The hood should be able to withstand the effects predicted in 5 and 6 .

f. Structural damage due to all causes should not be detrimental to the safe operation of the hood if consecutive explosions occur.

8. If the hood does not meet the requirements in step 7, it should be redesigned.

9. Sufficient air should flow into the hood to ensure complete combustion. This will prevent explosions within the offgas treatment system caused by combustion.

10. The offgas treatment system should be designed to withstand the maximum possible pressure established in step 5. This includes the seals and pipe materials.

11. Structural damage due to any pressure variations should not be detrimental to the safe operation of the offgas treatment system if consecutive explosions occur.

12. The issue is closed when a hood and offgas treatment system have been designed to meet all of the given criteria for a design basis explosion. ${ }^{4}$

\subsection{Breach of Pressurized Sealed Containers-}

1. Revicw the literature on ISV tests performed on sealed containers and determine applicability to TRU-PTs. Specifically, tests on 55-gal drums, containers with sludges, and containers with organic material should be reviewed. 
2. Determine the effects of container size, thickness, and material; waste material and volume; depth; and corrosion on the release rates of vapor. This can be done through use of computer simulations and engineering scale tests. These tests and simulations are performed to understand the basic physics of vapor release from sealed containers.

3. Using characterization data from the TRU-PTs, simulate breaches in containers filled with typical TRU-PT waste.

4. Estimate the maximum pressure and vapor release that can occur. Calculate the uncertainty of the estimations. If the hood and offgas treatment system are capable of handling the pressure and flow rates, then the issue is closed.

5. If the hood is not capable of handling the pressure, redesign the hood.

6. If the offgas treatment system is not capable of handling the pressure, redesign the offgas treatment system. A design under consideration is to place four offgas treatment system trailers in parallel. If the offgas flow rates exceed the capacity of one offgas treatment system, two or more could be used to handle and treat the waste. ${ }^{8}$

\subsection{Void Volumes-}

1. Through current and future characterization data, determine the location and size of the voids throughout the melt. Most of the void space is from empty and partially filled 55-gal druns. Due to direct dumping as opposed to stacking, there should be additional void space.

2. Based on the findings of part 1 , numerically estimate the maximum vapor flow rate and maximum pressure magnitude. Calculate the uncertainty of the estimations.

3. If the flow rate or pressure magnitude exceeds the safety design of the hood, redesign the hood.

4. If the flow rate or pressure magnitude exceeds the safety design of the offgas treatment system, redesign the system. A single large-scale system is capable of processing vapor releases from void volumes of $4.3 \mathrm{~m}^{3}$. This is assuming a design factor of 2 and the gases are uniformly released during a 5 -second period as the molten glass fills the void. ${ }^{6}$

\subsection{Combustion-}

1. Characterize the TRU-PTs to be vitrified for all explosive, combustible, and pyrophoric materials.

2. Determine the mechanism of pyrolysis and combustion for the organic and/or combustible materials found. This can be achieved experimentally or through a literature search.

3. Determine the magnitude and temporal range of the pressure transients that may occur within the hood due to combustion and/or explosion of the materials within and above the melt. Calculate the uncertainty of the estimations.

4. Perform numerical analyses of the offgas into the hood to determine if the hood design used in the ISV process is capable of handling the pressure transients due to combustion. Perform numerical analyses of the offgas from the hood to determine if the offgas treatment system design used in the ISV process is capable of handling the pressure transicnts due to combustion. Perform uncertainty analyses on the results. 
5. If not, redesign the hood and/or offgas treatment system to handle the pressure transients expected.

\subsection{Waste Falling from Sidewall onto the Melt Surface-}

1. Characterize the contents of the TRU-PT's to be vitrified. Contents and containers that could generate large volumes of gas should be known. Also, porosity of the soil should be determined.

2. Calculate the amount of subsidence based on a typical ISV run. Using the sluff angle of the soil, calculate the potential amount of soil that could fall on the melt.

3. Estimate the maximum volume of gas that would be generated based upon the site characterization data from step 1 and upon the amount of soil found in step 2.

4. Estimate the maximum hood pressure and the hood's ability to maintain its integrity, based on the gas generation estimate from step 3. Calculate the uncertainty of the results.

5. Calculate the amount and thermal condition of the gases leaving the hood. Maximum offgas treatment pressures should be estimated and the ability of the offgas treatment system to maintain its integrity evaluated.

6. If a hood exists or can be designed to handle the pressures from step 4 , this issue is closed.

7. If the offgas treatment can be designed or exists to meet the maximum pressures established in step 4, the issue is closed.

\subsubsection{Related Technical Issues}

3.2 Hood and Offgas Treatment System Seals Maintain Integrity.

\subsubsection{References}

1. M. A. Cook, The Science of High Explosives, Reinhold, New York, 1959, pp. 1-8.

2. W. E. Baker et al., Explosion Hazards and Evaluation, Elsevier Scientific Publishing Company, New York, 1983, p. 17.

3. Letter report from J. W. Shade, R. K. Farnsworth, C. H. Kindle, Pacific Northwest Laboratory, to EG\&G Idaho, Inc., "Technical Issues for ISV Processing of Buricd Waste Sites," April 1990.

4. C. M. Stoots, In Situ Vitrification Melt and Confinement Hood Performance Review, EGG-WM-9047, DOE Contract No. DE-AC07-76ID01570, September 1990.

5. "In Situ Vitrification Test Failures Forcing Reevaluation of Process," Report on Defense Plant Wastes, August 16, 1991, p. 143.

6. J. L. Buelt, V. F. FitzPatrick, C. L. Timmerman, J. G. Carter, and K. H. Oma, In Situ Vitrification of Transuranic Waste: An Updated System Evaluation and Applications Assessment, PNL-4800, March 1987.

7. D. A. Lamar and T. J. McLaughlin, Safety Analysis Documentation: Large-Scale Radionctive Testing of the In Situ Vitrification Process at the 216-Z-12 Crib, Pacific Northwest Laboratory, May 1987, p. 43. 
8. Personal communication with Paul Sloan, October 1991.

9. T. E. Wierman, ISV Field Test Siting and Source Term, EG\&G Idaho, Inc., EDF No. BWP-ISV-024, March 1990.

10. J. D. Buckmaster, The Mathematics of Combustion, Siam Publishers, Philadelphia, 1985. 


\subsection{Risks Due to Exposed Waste Are within Acceptable LImits}

\subsubsection{Description}

This technical issue has been identified to address the potential risks that may result from cxposed, untreated hazardous or radioactive contaminants during ISV remedial operations. Three specific mechanisms are addressed here:

- Contaminants released due to excessive subsidence and potential collapse of the sidewalls with resulting breach of hood containment

- Contaminants released from the melt and/or hood containment during post-processing operations

- Contaminants in the offgas are not treated adequately by the system and are released out of the stack.

\subsubsection{Description of the Issue.}

3.4.1.1.1 Excessive Subsidence and Sidewall Collapse-Excessive subsidence could occur if the lateral spread of the melt exceeded the boundaries of the hood, causing settling of the soil and waste beyond the hood walls, possibly resulting in a breach of hood containment.

Du:ing previous ISV operations, the melts spread downward and laterally to form bowl-shaped molten zones that have subsided from the ground level. Usually, areas of ground subsidence were backfilled with uncontaminated soil. Thus, during typical ISV operations, exposure of untreated waste did not occur. However, conditions at the TRU-contaminated pits and trenches are complex and unique compared to previous applications. The TRU-contaminated pits and trenches contain a multiplicity of hazardous, nonhazardous, and radioactive waste consisting of large inclusions of metal and other debris, breached drums, voids, migrating contaminants, possible concentrated pockets of organic solvents and combustibles, and varying void fractions. Lack of existing data because of undocumented waste disposal practices further complicates the situation. These conditions increase the risks of exposing waste during application of the ISV process compared to previous applications.

3.4.1.1.2 Post-Processing Containment-Hood containment of radioactive and/or hazardous contaminants is not only necessary during the ISV melting process bur also required after the melt is complete. Vapors and particulates generated during the melt process are confined by the hood and then processed by the offigas treatment system. Once power to the clectrodes is terminated, the contaminant release from the melt zone decreases exponentially with time." Modeling predicts that contaminant release rates become negligible within 4 hours after power to the electrodes is terminated. ${ }^{1}$ Remaining vapors and particulates need to be processed by the offgas treatment system before the hood can be safely removed. Hood removal involves accessing the hood, equipment disassembly, and, possibly, hood decontamination and fixation. Premature access to the hood after the melt process is complete has the potential consequence of causing serious injury to ISV workers, including death. Premature hood removal could also release airborne contaminants, which might result in unacceptable occupational, public, and environmental exposurc.

3.4.1.1.3 Inadequate Offgas Treatment-The currently designed offgas treatment systems for ISV field testing performs several unit operations to ensure the gases can be safely released out the stack. These operations include (a) supply sufficient flow rate to maintain a vacuum and supply excess oxygen to the confinement hood, and (b) cooling, scrubbing, and filtering the offgas to remove hazardous and/or radioactive wastes from the offgas. Failure of these operations could rosult in release of inadecirately treated offgas to the environmen!. 
3.4.1.2 Importance. This issue is significant because of the probability that ISV workers and the environment may be exposed to radioactive/hazardous contaminants. With proper protection, such as anti-C clothing, respirators, radiation monitors, and barrier ropes, unplanned exposure of workers to radioactive/hazardous waste can be prevented, thereby reducing the risk. ${ }^{2}$ However, releasing contaminants to the environment has other potentially significant consequences, such as increasing remediation costs, requiring further environmental remediation, exposing the general public to unnecessary radiation, and risking technology rejection by local, State, and Federal agencies. Assuring that risks due to any exposed waste are within acceptable limits requires that ISV operations meet the appropriate or relevant and applicable requirements (ARARs) for radioactive and/or hazardous contaminants.

\subsubsection{Influencing Factors.}

3.4.1.3.1 Excessive Subsidence and Sidewall Collapse-A number of factors must be considered that may contribute to the probability of subsidence and sidewall collapse.

a. Potential for Volume Reduction. TRU-contaminated pits and trenches contain substantial void fractions (e.g., empty drums and boxes) and large amounts of combustibles (e.g., large quantities of organic solvents). These conditions may cause a large reduction in volume during processing, increasing the subsidence.

b. Melt Geometry. Melt geometry is affected by many things, including the waste forms in the treatment zone, characteristics of the soil, ${ }^{j}$ rate of the melt, power applied, and temperature produced during the ISV process. Melt geometry is important because a melt that spreads beyond the hood boundaries has the possibility of causing subsidence in areas surrounding the hood, which may result in a breach of hood containment. Controlling the size, shape, and spread of the melt is important in preventing excessive lateral melt movement.

c. Composition, Location, and Concentration of Buried Waste. The overall risk of exposing waste depends heavily upon the amounts and types of organic solvents, toxic metals, radionuclides, and metal debris buried in the soil. The TRU-contaminated pits and trenches contain numerous types of buried waste. Location of specific waste types relative to the sidewalls and subsidence also impacts the consequences of exposure. High concentrations of contaminants located in the overburden next to a subsidence may increase the probability of exposure.

d. Cold Cap Rehavior. A rising cold cap can bring up untreated waste above the original soil surface, complicating closure procedures and increasing the potential for future ground subsidence. (During one initial ISV test, a cold cap of porous molten soil formed on the surface of the melt and rose above the original soil surface ${ }^{3}$ ) A rising cold cap should not be a problem at the TRU-contaminated pits and trenches, since ISV techniques have been devcloped to control cold cap subsidence (e.g., graphite electrodes and surface insulation ${ }^{1}$ ). The oxidizing/reducing potential of TRU-contaminated pit and trench soil needs to be deter mined to help predict cold cap behavior. Soils with an oxidizing/reducing condition could contribute to a glass-like foaming, causing unexpected melt expansion and rising.

3.4.1.3.2 Post-Processing Containment-The following factors may influcnce post-processing hood containment procedures.

j. Soil moisture, composition, stratigraphy, density, disturbance (e.g., from previous drilling activities). stiiiwasic ratio, (iepen to waste materiai, depin to basalt, groundwater location, hydraulic conductivity, thermal conductivity, clectrical conductivity, viscosity, and specific heat all affect the iSV process. 
a. Concentration of Buried Waste. The amount of contaminants entrained in the hood and offgas system is heavily dependent upon the amount of organic solvents, toxic metals, radionuclides, metal debris, and other waste buried in the soil. Processing buried waste will likely deposit hazardous and/or radioactive particulates on the hood walls, requiring hood decontamination and contamination fixation activities. Without proper safety measures, this could expose ISV workers to radioactive/hazardous chemicals.

The length of post-processing hood containment (time hood containment is necessary after the melt process is complete) also depends on the type and amount of buried waste, since variations in waste composition and its offgas products may affect the processing abilities of the offgas treatment system.

b. Excessive Subsidence. Time of hood removal also depends upon the amount of subsidence that occurs during and/or after the melt process. Excessive subsidence could result in exposure of radiological/hazardous waste from unprocessed waste remaining either in the sidewalls or on top of the cold cap (from sidewall collapse). Premature hood removal after excessive subsidence could expose ISV workers and the environment to radioactive/hazardous waste.

c. Cold Cap Formation. The formation of a suitable cold cap acts as a barrier to vapor release. Improper formation of a cold cap impacts post-processing hood containment by lengthening the time needed to process offgas vapors, thus increasing the necessity for hood containment.

3.4.1.3.3 Inadequate Offgas Treatment-A number of factors influence the treatment of offgas from the melt process.

a. Offgas Composition. The offgas comprises vapors generated within the ISV melt, particles entrained within the vapors, and products from combustion within the hood. Vapors generated within the ISV melt are due to the pyrolysis of organic materials, voids, and soil/waste moisture. Combustibles can pyrolyze and produce gases that combust in the hood environment, producing potentially hazardous or regulated compounds. Pyrolysis products can also react with adjacent material (e.g. nitrates) to form hazardous compounds that may be released into the melt.

b. Offgas Flow Rate. To maintain the vacuum within the hood, effectively treat the offgas, and supply sufficient oxygen for combustion, the flow rate of the offgas must be controlled. The flow rate is also impacted by the quantity of gases and combustion products being produced in the hood. Flow rate can impact the combustion process in the hood as well as the treatment system component efficiencies.

\subsubsection{Closure Requirements and Roadmap}

3.4.2.1 Assumptions. Analysis of this technical issue is based on several assumptions regarding the nature and contents of the TRU-PTs. Available data from Pit 9 contents have been used to characterize the "typical" TRU-PT. The contents of Pit 9 have been qualitatively characterized from existing records. The contents include hazardous organic compounds (volatile organic compounds, waste oil, PCBs, alcohols, acids), hazardous inorganic compounds (asbestos, nitrates, sodium compounds, caustics, lithium, beryllium, thallium), toxic metals (barium, chromium, arsenic, cadmium, silver, selenium, mercury), and "nonhazardous" waste with a great likelihood of being contaminated (paper, rags, wood, concrete, asphalt, glass, graphite, unirradiated fuel).

Pit 9 also contains large inclusions of metal and other debris (including drums, boxes, and cquipment). large void fractions (empty drums, boxes. etc.). possible concentrated pockets of organic solvents, combustibles, or radionuclides, or otherwise. (Records show that in Pit 9, deposition of 
drums and boxes were at times stacked and at other times randomly dumped, with much intermixing of container type. ${ }^{4}$ )

Because of the lack of documented waste disposal practices, determination of the actual amount of waste disposed of in the pits and trenches is not possible. Waste types and quantities are estimates only, based on sources, including Engineering Design Files (EDFs) ${ }^{5,6,7,8}$, the Radioactive Waste Management Information System (RWMIS), a report, ${ }^{9}$ and an internal letter ${ }^{10}$ by T. Clements, a collection of interviews with historical handlers, ${ }^{11}$ and an Annual Progress Report: FY-1987. ${ }^{12}$

3.4.2.2 Requirements and Stops to Close issue. Obtaining available TRU.PTs characterization data is the first requirement in closing this issue. Estimated waste types and quantities and soil characteristics as discussed earlier must be known to assist in predicting melt growth and subsidence. Knowledge of contaminants and their quantities can be used to predict offgas treatment system efficiency and to estimate the types and concentration of contaminants that may build up within the hood.

This knowledge can be used to select the appropriate solvents and fixation agents needed for hood decontamination and fixation. Also, buried waste data can be used to choose effective "barriers" (such as anti-C clothing, respirators, and radiation and gas monitors) to prevent workers from exposure and to prevent a release of contaminants during hood access activities.

\subsection{Excessive Subsidence and Sidewall Collapse-}

1. Use present ISV process models with site characterization data to predict the amount of volume reduction. TRU.PTs that contain substantial void fractions or considerable amounts of combustibles have a greater likelihood of causing a large reduction in surface volume during processing, increasing the chance for excessive subsidence. Pit 9 is known to contain 1,302 boxes of empty drums ${ }^{4}$ (substantial void fractions) and an estimated 18,724 gal of hazardous organic waste ${ }^{13}$ (possible concentrated pockets of combustibles). These factors give great potential for a large volume reduction at Pit 9 during ISV processing. Void fractions and the types and quantities of combustibles need to be estimated for the other TRU-PTs to predict accurately the volume reduction that may occur during ISV processing.

2. Use existing ISV process models and data from past ISV operations with the site characterization data to predict melt geometry. Use available ISV operating controls and measurements to govern the size and the shape of the melt during processing (e.g., pretest waste configuration data, electrode power and temperature, on-line measurements of melt).

3. Use the appropriate techniques to govern cold cap formation (graphite collars and surface insulation ${ }^{2}$ ). Since graphite is used in the glass industry as a reducing agent to control gas bubble generation, the use of graphite electrodes and collars should alleviate or regulate foaming of the melt product.

4. Implement effective monitoring equipment. Perhaps the greatest mitigation factor in preventing exposure of contaminated waste may be the use of effective monitoring equipment. Monitoring equipment could warn of excessive lateral melt movement before excessive subsidence could occur. Reducing or shutting down power to the electrodes might alleviate the hazard of exposing untreated waste. Once power to the electrodes is terminated, contaminant release from the melt zone decreases exponentially with time, and contaminant release rates become negligible $O$ to 4 hours after power is terminated. ${ }^{\text {i2 }}$ In the event of excessive subsidence, shutting down the power to the electrodes would reduce the risk of contaminant release to the environment. 


\subsection{Post-Processing Containinent-}

1. Use modeling techniques and lab-scale tests with site characterization data to predict amounts and types of contaminants that may be released from the melt after power to electrodes is terminated. These data are important for estimating the types and concentrations of contaminants that could accumulate in the hood after the melt is complete, estimating the required offgas post-processing, and mitigating premature hood removal.

2. Review existing ISV literature and data, specifically, performance analysis data for offgas hood containment and offgas treatment system efficiency relative to the conditions expected at the TRU-PTs. Determine if the current procedures used for hood access, decontamination, disassembly, and removal are viable for ISV operations at the TRU-PTs.

\subsection{Inadequate Offgas Treatment-}

1. Use existing ISV process models with waste characterization data to predict the composition and amounts of melt offgases, including the products of combustion within the hood and particulates.

2. Evaluate the effectiveness of the offgas treatment system using the INEL PULSE code ${ }^{k}$ as modified for ISV operations. Inability of the existing system to adequately treat the offgas stream may require modifications to the system.

\subsubsection{Related Technical Issues}

3.2 Hood and offgas treatment system seals maintain integrity.

3.3 Hood and offgas ireatment system handle pressure transients.

\subsubsection{References}

1. D. A. Lamar and T. J. McLaughlin, Large-Scale Radioactive Testing of the In Situ Vitrification Process at the 216-Z-12 Crib, Safety Analysis Documentation, PNL, DOE Contract No. DE-AC076RLO 1830, May 1987, pp. 49-50.

2. T. E. Wierman and C. Sullivan, Initial Probabilistic Risk Assessment of the In Situ Vitrification Large Field Tesi, Volume Three: Industrial Safety, EGG-SSRE-PRA-001-90, September 1990.

3. J. L. Buclt and J. G. Carter, In Situ Vitrification Large-Scale Operational Acceptance Test Analysis, PNL-5828, May 1986, pp. 33-34.

4. EG\&G Idaho, Inc., History of Buried Transuranic Waste at the INEL, WMP 77-3, March 1977, p. 23.

5. T. E. Wierman, ISV LFT Siting Requirements and Selection, EG\&G Idaho, Inc., EDF No. ERP-ISV-032, March 1990.

6. E. C. Garcia and J. L. Knight, EPA Toxic and Ordinary Metal Content in Pit 9, EG\&G Idaho, Inc., EDF No. BWP-ISV-001, January 1989.

k. PULSE, developed by the INEL, Version 1.0.0, Modification ISV, October 23, 1991. 
7. E. C. Garcia and J. L. Knight, Hazardous Organic Content of Pit 9, EG\&G Idaho, Inc., EDF No. BWP-ISV-002, January 1989.

8. E. C. Garcia and J. L. Knight, Hazardous Inorganic Content of Pit 9, EG\&G Idaho, Inc., EDF No. BWP-ISV-003, January 1989.

9. T. L. Clements, Jr., Content Code Assessment for INEL Contact-Handled Stored Transuranic Wastes, WM-F1-82-021, October 1982.

10. T. L. Clements, Jr., EG\&G Idaho, Inc., to C. J. Bonzon, EG\&G Idaho, Inc., Subject: "Buried Sludge Waste Characterization," TLC-29-88, May 2, 1988.

11. EG\&G Idaho, Inc., Environmental Restoration Program BWP Interviews of Historical Waste Handlers, Books 1 and 2, 1989.

12. P. T. Laney et al., Annual Progress Report: FY-1987, Subsurface Investigations Program at the Radioactive Waste Management Complex of the Idaho National Engineering Laboratory, DOE/ID-10183, 1988.

13. EG\&G Idaho, Inc., Remedial Investigation/Feasibility Study Work Plan of the Subsurface Disposal Area Radioactive Waste Management Complex at the INEL, EGG-WM-8776, December 1989, Section 3, p. 36. 


\subsection{Electrical Hazards Are Controlled}

\subsubsection{Description}

3.5.1.1 Description of the Issue. Equipment used to date for ISV has been designed and built to requirements of the National Electrical Code (NEC) and other codes and standards relative to electrical equipment. It is therefore assumed that electrical hazards associated with normal operation of lights, electrical heaters, transformers, and offgas system pump motors are no greater than would be expected for any other industrial operation. However, some electrical hazards identified are somewhat unique to ISV. These hazards include:

1. Accidental power-up of the system when electrodes are being lengthened.

2. The metal containment hood and/or surrounding support structure becoming electrically energized.

3. Catastrophic failure of electrical power supply equipment.

4. The possibility of stray currents. This includes both the possibility of stray current corrosion and the high-energy stray currents that could be hazardous to personnel and equipment.

3.5.1.2 Importance. The importance of this issue arises from the threat of electrical shock to ISV workers from electrical mishaps. Worker safety should be of highest priority when conducting ISV tests. The first three hazards can be controlled by the use of proper safety measures. Electrical shock hazards during ISV setup, operation, and maintenance (including the electrical shock hazard that could result during electrode lengthening) can be controlled by separation of operations from overhead power lines and insulation of conductors. Insulation of conductors should be inspected and tested. Only authorized personnel using electrical gloves and rubber shoe covers should be permitted in the controlled area during ISV operations. Lock and tag procedures and protective equipment should be used when working on electrical systems. Specific health and safety plans will give detailed information on the personnel protective measures and the emergency plans needed during ISV tests.

The fourth hazard is important because stray currents from ISV activities at the Radioactive Waste Management Complex could potentially cause corrosion and perforation of underground metal structures for miles around. Examples of structures that could be affected are underground storage tanks, double-walled pipes at the Idaho Chemical Processing Plant (ICPP) that carry mixed hazardous wastes, and emergency firewater pipes. "Stray electrical currents are those that follow paths other than the intended circuit, or they may be any extraneous currents in the earth. If currents of this kind enter a metal structure, they cause corrosion at areas where the currents leave again to enter the soil or water." ${ }^{1}$ Stray currents can travel underground for miles if they have conductive paths (e.g., metal pipes, or in the case of RWMC, an aquifer). During the Intermediate Field Test (IFT) at Test Area North (TAN), Westinghouse Idaho Nuclear Company, Inc. (WINCO) personnel in charge of maintaining the cathodic protection system at ICPP placed a potentiometer on a pipe to determine whether the IFT affected the voltage readings. A $0.15-\mathrm{V}$ increase was detected, but the readings were taken at such intervals that it was not known whether the IFT was the proximate cause of the voltage increase. [Note that the test site (TAN) was more than $20 \mathrm{mi}$ from the place at which the voltage increase was detected (ICPP)].

The full-scale ISV process uses $5 \mathrm{MW}$ (about $2,200 \mathrm{~V}$ at 2,200 A) to vitrify the ground, increasing the possibility of an ISV operation causing a significant electrical stray current. The amount of metal corroded, or wasted, is proportional to the amount of current that leaves the structure. Stray current corrosion is concentrated at the point of exit from the metal structure, so 
the damage takes the form of pitting rather than general attack.' Therefore, even small currents can cause perforation quickly (depending on the thickness of the metal being attacked).

3.5.1.3 Influencing Factors. The influencing factor for this issue is whether all possible conducting paths for stray currents can be defined.

The conductive contents of the TRU-PTs should be known to evaluate the possible conduction paths. A metal pipe or a saturated zone can act as a conductive path. In this case, a saturated zone is defined as any region with accumulated water (perched water zone) or conductive chemicals. The location of the saturated zone in relation to the electrodes, the possible melt depth, and any conductive objects within the melt should be known.

\subsubsection{Closure Requirements and Roadmap}

3.5.2.1 Assumptions. It is assumed that electrical hazards associated with normal operation of lights, electrical heaters, transformers, and offgas system pump motors are no greater than would be expected for any other industrial operation and can be controlled through the use of proper safety precautions as established in OSHA and NFPA guidelines.

It is assumed that accidental power-up of the system when electrodes are being lengthened, the metal containment hood and/or surrounding support structure is becoming electrically energized, or catastrophic failure of electrical power supply equipment is occurring can be controlled through the use of proper safety measures.

It is assumed that the contents of the area to be vitrified can be known well enough to establish possible conduction paths. It is also assumed that enough information about the surrounding geology can be gathered to determine possible soil or saturated zone conduction paths and that no significant stray currents will be generated by explosions within the melt.

3.5.2.2 Requirements and Steps to Close Issue. As stated carlicr, most of the electrical hazards can be controlled through proper safety measures. However, the issue of stray currents requires additional steps to resolve:

1. Conduct ISV field tests (in conjunction with resolution of the other issues).

2. Identify structures at different distances and depths that will be monitored. Measurements should be made on these structures before and after the ISV test.

3. Monitor those structures continuously with recording instruments to measure the change in potential and current during the ISV experiment.

4. Compare the records to the duration of the ISV experiment.

5. If stray currents are detected, consult experts in cathodic protection to determine the following:
a. Severity of the problem
b. Ways to mitigate the effects.

\footnotetext{
1. Personal communication with R. E. Minzia, Westinghouse Idaho Nuclear Company, Inc. (WINCO), Idaho) Falts, Idaho, August 1990.
} 


\subsubsection{Related Technical lssues}

None.

\subsubsection{References}

1. H. H. Uhlig and R. W. Revie, Corrosion and Corrosion Control, 3rd edition, Wiley, New York, 1985, p. 120. 

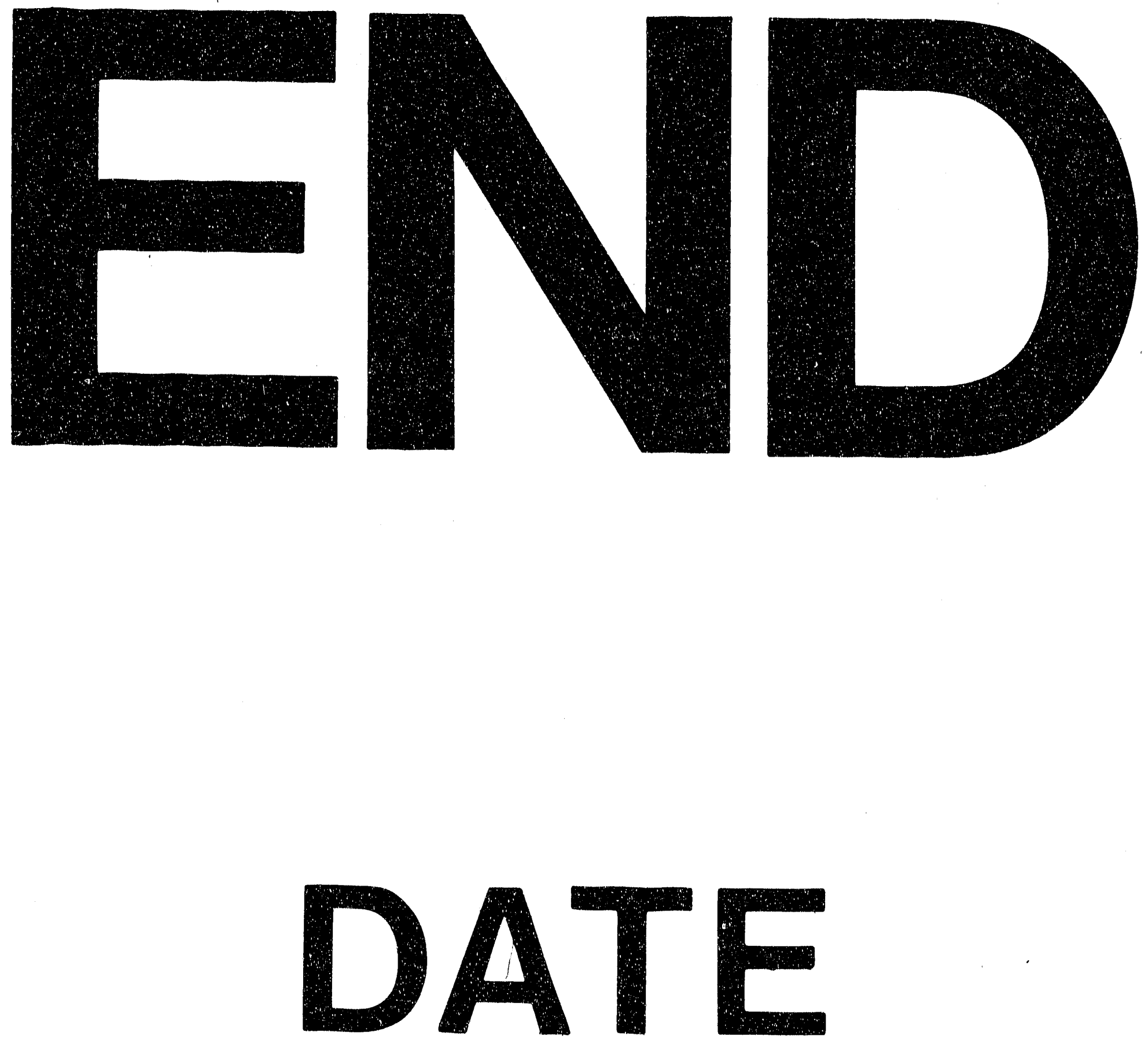

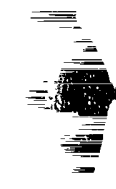
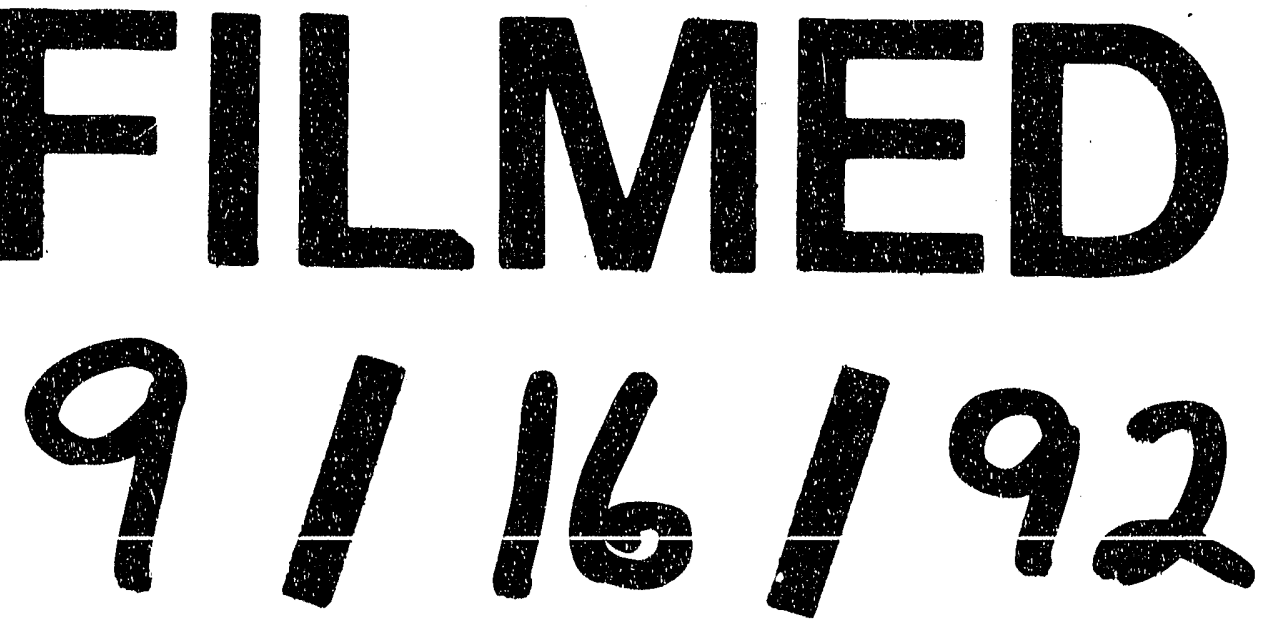
